\title{
p140Cap Regulates Memory and Synaptic Plasticity through Src-Mediated and Citron-N-Mediated Actin Reorganization
}

\author{
Daniele Repetto, ${ }^{1,7 \star}$ Paola Camera, ${ }^{1 \star}$ Riccardo Melani, ${ }^{3,4}$ Noemi Morello, ${ }^{2}$ Isabella Russo, ${ }^{1}$ Eleonora Calcagno, ${ }^{2,5}$ \\ Romana Tomasoni, ${ }^{6}$ Federico Bianchi, ${ }^{1}$ Gaia Berto, ${ }^{1}$ Maurizio Giustetto, ${ }^{2}$ Nicoletta Berardi, ${ }^{3,4}$ Tommaso Pizzorusso, ${ }^{3,4}$ \\ Michela Matteoli, ${ }^{6}$ Paola Di Stefano, ${ }^{1}$ Markus Missler, ${ }^{7}$ Emilia Turco, ${ }^{1}$ Ferdinando Di Cunto, ${ }^{1}$ and Paola Defilippi ${ }^{1}$ \\ ${ }^{1}$ Molecular Biotechnology Center, Department of Molecular Biotechnology and Health Sciences, ${ }^{2}$ Department of Neuroscience, University of Torino, 10126 \\ Torino, Italy, ${ }^{3}$ Institute of Neuroscience of the National Research Council of Italy, 56124 Pisa, Italy, ${ }^{4}$ Department of Neuroscience, Psychology, Drug \\ Research and Child Health (Neurofarba), University of Florence, 50135 Florence, Italy, ${ }^{5}$ National Institute of Neuroscience-Italy, 10125 Torino, Italy, \\ ${ }^{6}$ Department of Biotechnology and Translational Medicine, University of Milan, and Humanitas Clinical and Research Center, Rozzano, 20089 Milan, Italy, \\ and ${ }^{7}$ Institute of Anatomy and Molecular Neurobiology, Westfälische Wilhelms-University, D-48149 Münster, Germany
}

A major challenge in the neuroscience field is the identification of molecules and pathways that control synaptic plasticity and memory. Dendritic spines play a pivotal role in these processes, as the major sites of excitatory synapses in neuronal communication. Previous studies have shown that the scaffold protein p140Cap localizes into dendritic spines and that its knockdown negatively modulates spine shape in culture. However, so far, there is no information on its in vivo relevance. By using a knock-out mouse model, we here demonstrate that p140Cap is a key element for both learning and synaptic plasticity. Indeed, $p 140 \mathrm{Ca} p^{-1-}$ mice are impaired in object recognition test, as well as in LTP and in LTD measurements. The in vivo effects of p140Cap loss are presumably attenuated by noncell-autonomous events, since primary neurons obtained from $\mathrm{p} 140 \mathrm{Cap}^{-/-}$mice show a strong reduction in number of mushroom spines and abnormal organization of synapse-associated F-actin. These phenotypes are most likely caused by a local reduction of the inhibitory control of RhoA and of cortactin toward the actin-depolymerizing factor cofilin. These events can be controlled by p140Cap through its capability to directly inhibit the activation of Src kinase and by its binding to the scaffold protein Citron-N. Altogether, our results provide new insight into how protein associated with dynamic microtubules may regulate spine actin organization through interaction with postsynaptic density components.

Key words: actin cytoskeleton; Cit-N; p140Cap; Rho GTPase; Src; synapses

\section{Introduction}

Dendritic spines (DSs) are small protrusions of the dendrite shafts that develop at excitatory synapses and play a crucial role in neuronal communication by compartmentalizing the biochemical events activated by synaptic transmission (Hering and Sheng, 2001; Tada and Sheng, 2006). It is widely accepted that morphological and biochemical modifications of DSs underlie synaptic plasticity events (Matsuzaki et al., 2004;

Received June 3, 2013; revised Dec. 4, 2013; accepted Dec. 7, 2013

Author contributions: D.R., P.C., M.G., N.B., T.P., M. Matteoli, E.T., F.D.C., and P.D. designed research; D.R., P.C., R.M., N.M., I.R., E.C., R.T., F.B., G.B., P.D.S., and E.T. performed research; M. Missler contributed unpublished reagents/analytic tools; D.R., P.C., R.M., N.M., E.C., R.T., F.B., G.B., M.G., N.B., T.P., M. Matteoli, P.D.S., E.T., F.D.C., and P.D. analyzed data; D.R., P.C., F.D.C., and P.D. wrote the paper.

This work was supported by the Neuroscience Program of the Compagnia di San Paolo to P.D. and F.D.C., and by Compagnia di San Paolo, Progetto d'Ateneo, Università di Torino 2011 to P.D., F.D.C., M.G., and E.T. p140Cap knock-out analysis was also supported by the Associazione Italiana Ricerca Cancro (IG 11896) to P.D., by the Ministero Università Ricerca (PRIN 2010/2011) to P.D., by the Fondation Jerome Lèjeune to F.D.C., by Telethon Italy to F.D.C., and by Regione Piemonte (Drug Innovation and Discovery) to P.D. and F.D.C.

*D.R. and P.C. contributed equally to this work.

The authors declare no competing financial interests.

Correspondence should be addressed to either of the following: Ferdinando Di Cunto at the above address. E-mail: ferdinando.dicunto@unito.it; or Paola Defilippi at the above address. E-mail: paola.defilippi@unito.it.

DOI:10.1523/JNEUROSCI.2341-13.2014

Copyright $\odot 2014$ the authors $\quad 0270-6474 / 14 / 341542-12 \$ 15.00 / 0$
Tada and Sheng, 2006). Moreover, the importance of spines has been consistently documented in numerous disorders associated with intellectual disabilities, such as fragile X, Down and Rett syndromes, Alzheimer's disease, and autism (van Spronsen and Hoogenraad, 2010).

A tight control of actin dynamics is crucial for spine morphology and function (Star et al., 2002). As in other cellular districts, the polymerization and stabilization of the actin cytoskeleton in DSs is primarily controlled by the small GTPases RhoA, Rac1, and Cdc42 (Yoshihara et al., 2009). Accordingly, studies in animal models have revealed that the inactivation of Rho-GTPase regulators or of their effectors affects DS biogenesis, maintenance, and morphology, with strong effects on learning and memory (Rex et al., 2009; Murakoshi et al., 2011). The molecular networks controlling Rho-GTPase-dependent actin assembly in DSs are only partially characterized. It is commonly assumed that the main role is played by signaling events activated by synaptic transmission, but it is conceivable that cell-autonomous mechanisms may contribute as well. For instance, dynamic microtubules have been shown to regulate DS maintenance by locally regulating actin polymerization (Jaworski et al., 2009; Hu et al., 2011; Merriam et al., 2011; Lemieux et al., 2012). The +TIP (microtubule plus-end tracking protein) protein EB3 and its 
A

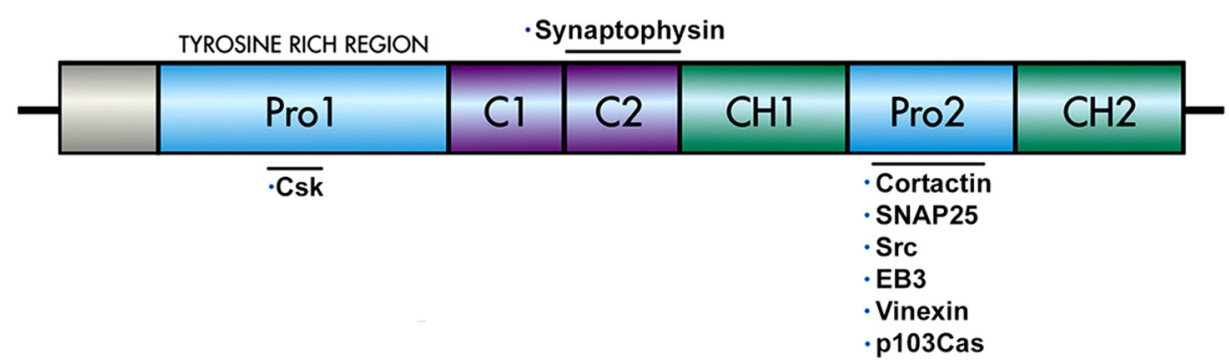

B Murine p140Cap gene
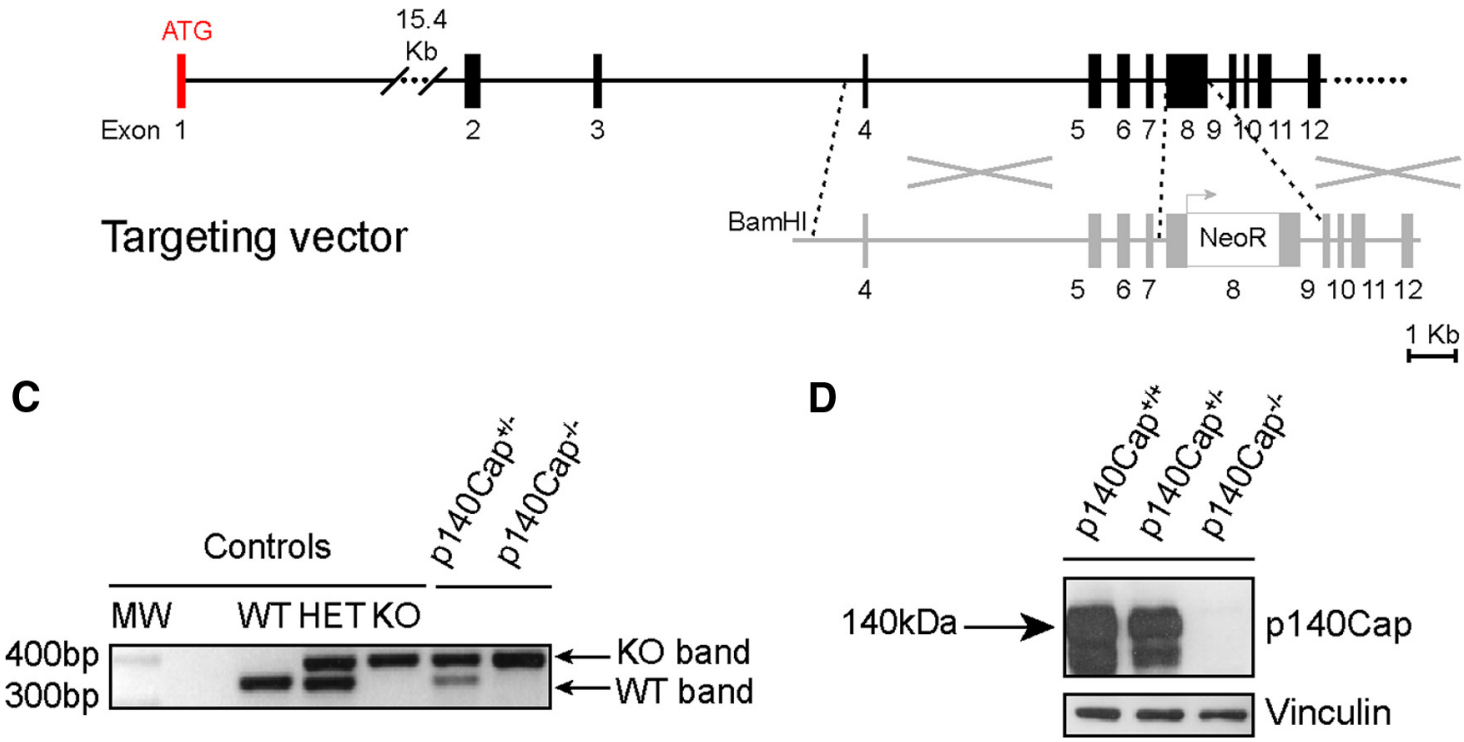

Figure 1. Generation and validation of p140Cap-deficient mouse model. A, Schematic representation of the domain structure and of the known interactors of p140Cap. Pro, Prolin-rich region; C1-C2, coiled-coil regions; $\mathrm{CH}_{1}-\mathrm{CH} 2$, charged regions. B, Schematic representation of mouse recombinant p140Cap construct; the neomicin cassette (NeoR) disruption was targeted into exon 8 of p140Cap gene on mouse chromosome 11. C, PCR screening of tail-derived genomic DNA from littermate bred from heterozygous mice. The controls showed in figure are vectors used for targeting strategy. $\boldsymbol{D}$, Western blot detection of p140Cap protein levels in total brain cell lysates from mice of the indicated genotypes.

interacting partner p140Cap play a major role in this process (Jaworski et al., 2009). Indeed, EB3 or p140Cap knockdown in primary hippocampal neurons lowered the number of mushroom spines and proportionally increased the number of dendritic filopodia (Jaworski et al., 2009), while p140Cap overexpression rescued the EB3 knockdown phenotype (Jaworski et al., 2009). Since p140Cap was also known as an inhibitor of c-Src (Di Stefano et al., 2007; Damiano et al., 2010, 2012), it was proposed that dynamic microtubules may affect actin polymerization through p140Cap-mediated Src regulation (Jaworski et al., 2009). However, the pathways leading from p140Cap to reorganization of DS actin remained substantially unexplored. Moreover, it remains to be elucidated whether the described events are relevant to the organization and function of DSs in vivo. In this study, we have addressed these issues by generating and analyzing p140Cap knock-out $\left(\right.$ p140Cap $\left.{ }^{-1-}\right)$ mice. We show that p140 Cap ${ }^{-1-}$ mice display specific learning defects, DS disorganization, and reduced LTP and LTD. Moreover, we demonstrate that the loss of p140Cap results in vivo in hyperactivation of Src kinases and we show that the defects in DS organization of p140 Cap ${ }^{-1-}$ primary neurons can be reverted by Src inhibitors. Finally, we characterized a RhoA-related molecular network by which p140Cap may regulate the maintenance of F-actin in DSs, centered on the RhoA-binding protein Citron-N (Cit-N).

\section{Materials and Methods}

Behavioral testing. For rota-rod test, mice were placed on a constantly accelerating rotating cylinder, and the latency to fall was counted as memory performance. After an initial training session (three trials with 5 min interval), the test was repeated every week on the same day for 5 weeks. Every session was divided into three trials of 5 min each with a recovery time of $5 \mathrm{~min}$ between trials. For object recognition test (ORT), the apparatus consisted of a square arena $(60 \times 60 \times 30 \mathrm{~cm})$ constructed in polyvinyl chloride with black walls and a white floor. The objects were cubes (12 cm wide) made of transparent Plexiglas that contained the visual patterns to be discriminated. The apparatus was placed in a silent room and a white tent, $2 \mathrm{~m}$ from the top of the apparatus, created a ceiling on which a video camera was mounted to record trials with EthoVision software (Noldus). Box and objects were cleaned up between trials to stop the buildup of olfactory cues. To avoid stress during the phases of the experiment, mice were habituated to remain in the empty arena for $15 \mathrm{~min}$ the day before training. In the sample phase, mice were allowed to explore two identical visual patterns in the arena for $5 \mathrm{~min}$. The goal of this phase was to enable the mice to familiarize themselves with their surroundings and build a memory trace. The test was conducted 1 and $24 \mathrm{~h}$ after the sample phase, changing one of the two patterns with a novel one that the mice had never seen before and allowing them to explore for $5 \mathrm{~min}$. For each phase of the experiment, the experimenter tracked the time spent by the mice exploring the objects with paws and muzzle.

Electrophysiology recording. Animals were anesthetized with isoflurane and decapitated. The brain was rapidly removed and placed in ice-cold 
A

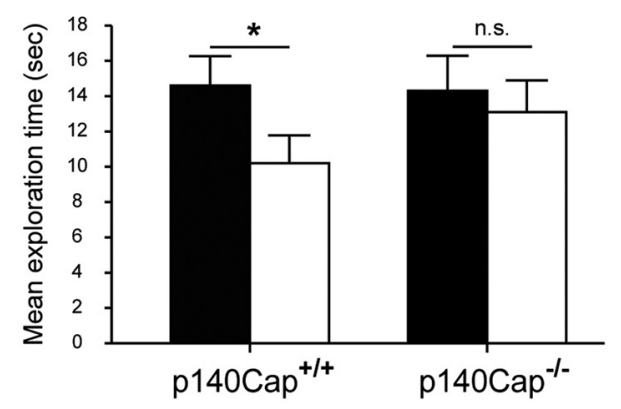

C
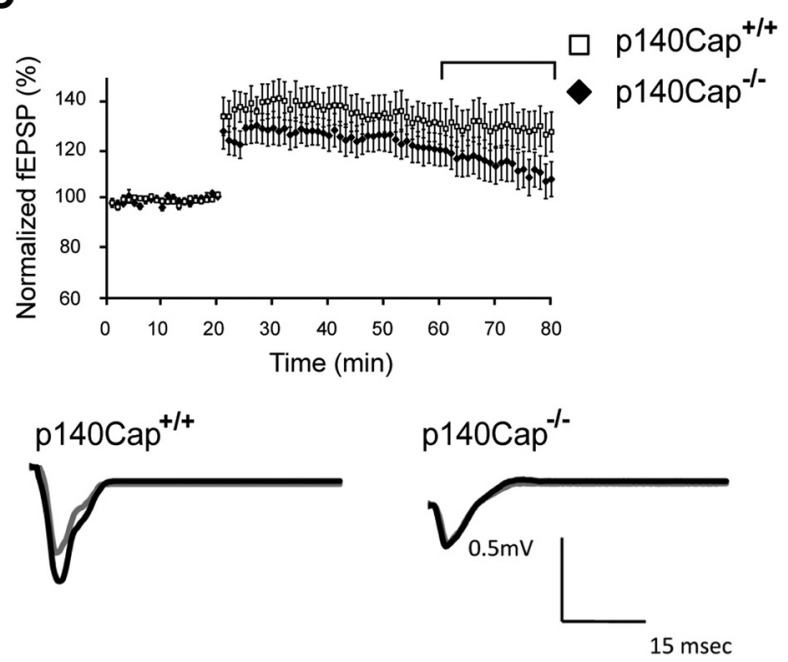

E

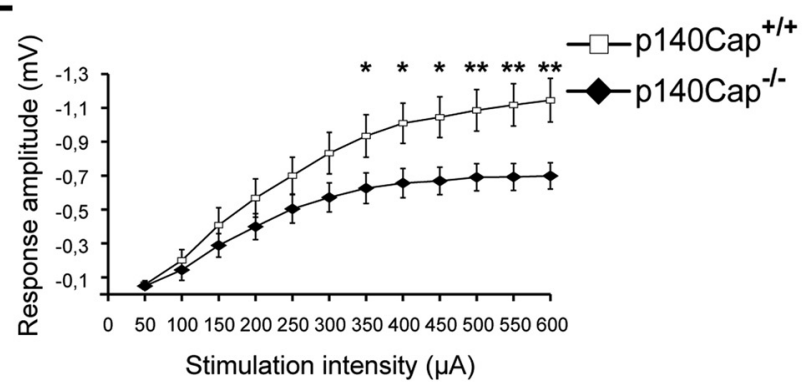

Rotarod Test

G

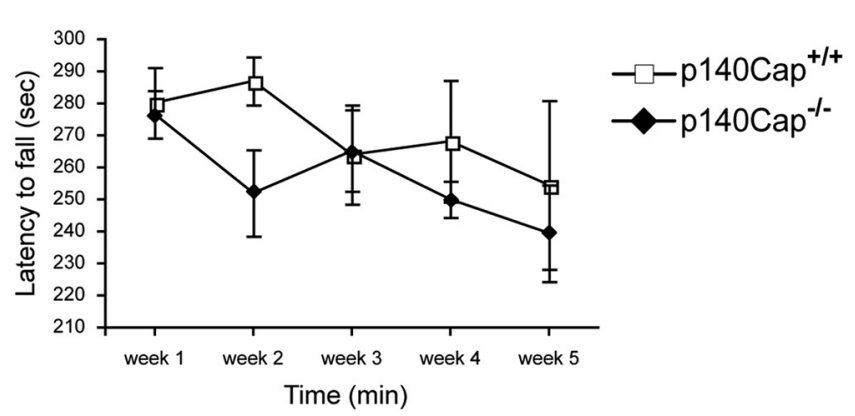

B

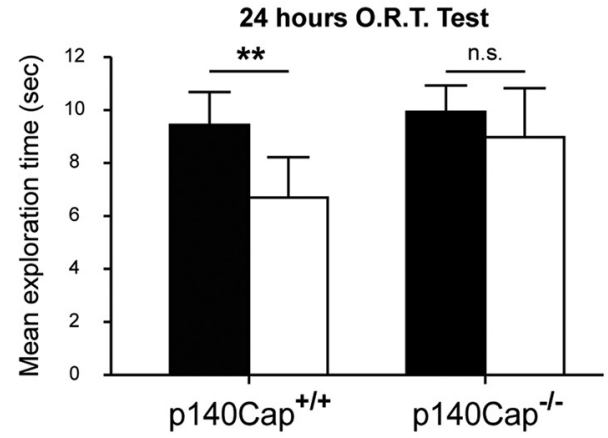

D

Long Term Depression
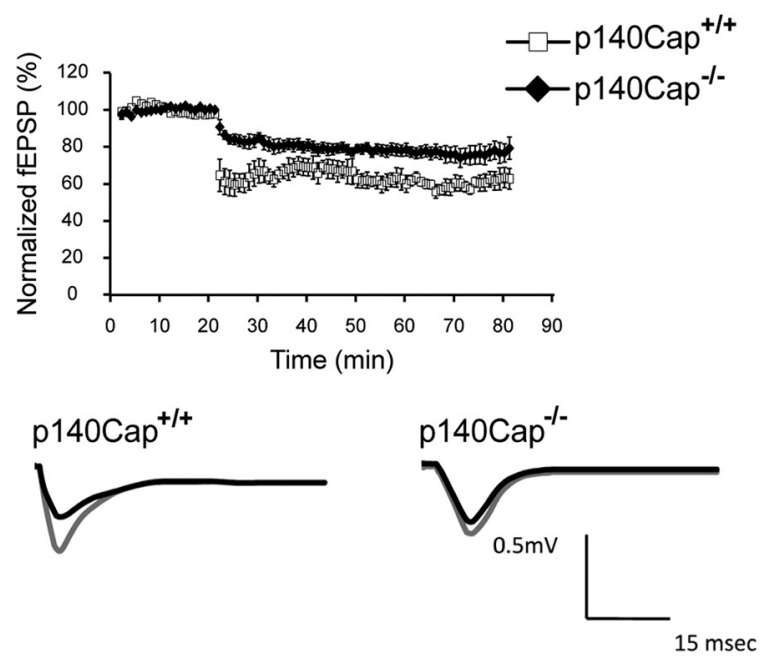

F

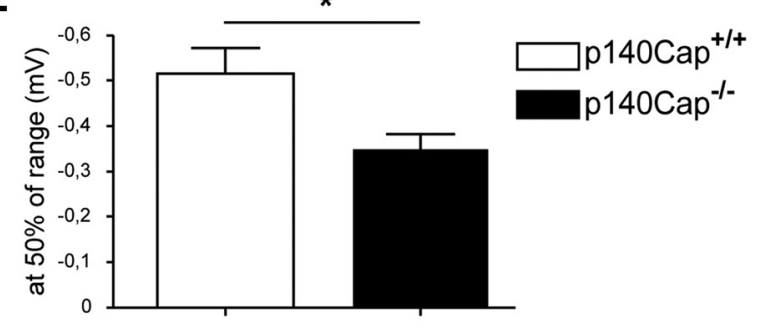

H

Rotarod Test in Trial 1

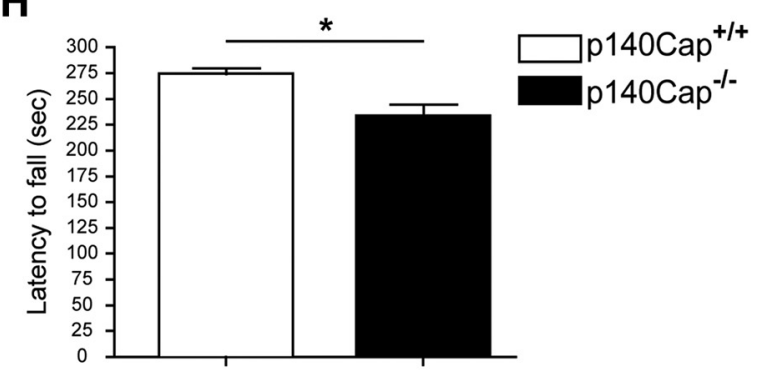

Figure 2. $\quad$ p $140 \mathrm{Cap}^{-/-}$mice display reduced memory consolidation and impaired synaptic plasticity. $A, B, p 140 \mathrm{Cap}^{-/-}$mice display impairment in visual ORT. After habituation and familiarization, when mice were tested in the ORT, mean exploration time for the novel object (open bar) was greater than for the familiar one (black bar) in p140Cap ${ }^{+/+}(n=14)$ but not in p140Cap ${ }^{-/-}$ mice $(n=14)$, both at $1 \mathrm{~h}(\boldsymbol{A})$ and at $24 \mathrm{~h}\left(\boldsymbol{B} ;\right.$ paired $t$ test, $p 140 \mathrm{Cap}^{+/+}$mice, $p=0.011$ and $p=0.002$ for 1 and $24 \mathrm{~h}$, respectively; $p 140 \mathrm{Cap}^{-1-}$ mice, $p=0.53$ and $p=0.55$ at 1 and $24 \mathrm{~h}$, respectively). ${ }^{*} p<0.05 ;{ }^{* *} p<0.01$; n.s., Nonsignificant. C, $\boldsymbol{D}, \mathrm{p} 140$ Cap is important for synaptic plasticity both of the LTD and of the LTP type. C, Mean normalized fEPSP amplitude is reported for p140Cap ${ }^{+/+}(n=10$ slices $)$ and $p 140 \mathrm{Cap}^{-/-}\left(n=11\right.$ slices) mice as a function of time. Paired $t$ test, last 15 min post-theta versus baseline in $p 140 \mathrm{Cap}^{-/-}$mice, $p>0.34 ;$ in $p 140 \mathrm{Cap}{ }^{+/+}, p=$ $0.004 ;$ t test, last $15 \mathrm{~min}, p 140 \mathrm{Cap}^{-/-}$versus $p 140 \mathrm{Cap}^{+/+}$mice, $p=0.032$. D. Mean normalized fEPSP amplitude is reported for $p 140 \mathrm{Cap}^{+/+}\left(n=5\right.$ slices) and $p 140 \mathrm{Cap}{ }^{-/-}(n=4$ slices) mice as a function of time. $t$ test, $p<0.001$; Mann-Whitney rank sum test. Sample traces are shown at the bottom of the two panels. Gray, Baseline activity; black, post-theta burst stimulus/lowfrequency stimulation. $\boldsymbol{E}, \boldsymbol{F}$, Basal synaptic transmission is reduced in perirhinal cortex of p140Cap ${ }^{-1-}$ mice. $\boldsymbol{E}$, Mean amplitude of layer II/III field potential (Figure legend continues.) 
cutting solution bubbled with $95 \% \mathrm{O}_{2} / 5 \% \mathrm{CO}_{2}$, as described previously (Cho et al., 2000). Vibratome slices $(350 \mu \mathrm{m})$ of perirhinal cortex were taken in the region -2.5 to $-4 \mathrm{~mm}$ rostral from bregma. Slices were stored submerged in bubbled, artificial CSF $\left(20-25^{\circ} \mathrm{C}\right.$, same composition as cutting solution, except $2 \mathrm{~mm} \mathrm{CaCl}, 1 \mathrm{mM} \mathrm{MgCl}_{2}$ ) for at least $1 \mathrm{~h}$ before the onset of recordings.

For extracellular field recordings, a single slice was placed in an interface recording chamber superfused by artificial $\operatorname{CSF}\left(30^{\circ} \mathrm{C}\right.$, flow rate $2 \mathrm{ml} / \mathrm{min}$ ). Evoked field EPSPs (fEPSPs) were recorded from layers II/III from directly below the rhinal sulcus (area 35). A stimulation electrode was placed in layer II/III on the temporal side $(0.5 \mathrm{~mm}$, area 36$)$ of the recording electrode. Stimuli ( $0.1 \mathrm{~ms}$ duration) were delivered to the stimulation electrode at $0.1 \mathrm{~Hz}$. Input-output curves were produced with stimulation intensities from 50 to $500 \mu \mathrm{A}$, in steps of $50 \mu \mathrm{A}$. For monitoring baseline synaptic transmission before LTP or LTD induction, fEPSPs were reduced to $50-60 \%$ of the maximum amplitude and recorded for at least $20 \mathrm{~min}$ ( $<10 \%$ amplitude change over $20 \mathrm{~min}$ ). For LTP induction, four stimulus trains were delivered at $0.066 \mathrm{~Hz}$. Each train comprised 10 bursts at $0.5 \mathrm{~Hz}$, and each burst contained four stimuli (1 ms) at $100 \mathrm{~Hz}$. For LTD induction, 900 stimulus pairs $(1 \mathrm{~ms}$ each, $20 \mathrm{~ms}$ interstimulus interval) were delivered at $2 \mathrm{~Hz}$. Subsequently, fEPSPs elicited by $0.1 \mathrm{~Hz}$ stimulation were recorded for another $60 \mathrm{~min}$.

Field potentials were amplified with an CyberAmp 320 (Molecular Devices) and recorded and analyzed with custom-made software written in LabView (National Instruments). For offline LTP/LTD analysis, fEPSPs were averaged across $1 \mathrm{~min}$ and the peak amplitude of the mean fEPSP was expressed relative to the preconditioning baseline.

DiOlistic labeling of brain structures. Fluorescence labeling of neuronal structures was performed as described previously (Pavlowsky et al., 2010; Chapleau et al., 2012). Briefly, DiI (Invitrogen) was dissolved in methylene chloride (Supelco) and then gently dropped onto the tungsten particles (1.3 mm in diameter; Bio-Rad). p140Cap ${ }^{+/+}$and p140 Cap $^{-/-}$ littermates (five animals per genotype) were anesthetized with an intraperitoneal injection of chloral hydrate and perfused with PBS, and then with $4 \%$ PFA in $0.1 \mathrm{M} \mathrm{PB}$. Brains were postfixed in the same fixative solution, washed several times in PB $0.1 \mathrm{M}$, and then cut into $300 \mathrm{~mm}$ sections on a vibratome (Leica VT 1000S). The particles were accelerated with inert helium gas (120 psi). After the shot, the slices were placed in $4 \%$ PFA for $2 \mathrm{~h}$, washed three times in PB $0.1 \mathrm{M}$, mounted on glass slides, and observed through a Zeiss LSM-5 Pascal confocal microscope. Images from fluorescently labeled secondary and tertiary branches of dendrites in the stratum radiatum of CA1 area in the hippocampus and layer $\mathrm{V}$ of the $\mathrm{S} 1$ cortex were acquired. To generate the dataset, $\geq 10 z$-stack images consisting of $10-15$ sections $(512 \times 512$ pixels, $80-100$-mm-long dendritic segments) spaced $0.5 \mathrm{~mm}$ apart were collected for each animal and for each area analyzed. Dendritic segments and spines were analyzed quantitatively with ImageJ software 1.34S (National Institutes of Health, public domain), with the observer blinded to the experimental conditions. All dendritic protrusions with a clearly recognizable neck connected to the shaft of the dendrite were counted as spines.

Primary rat and mouse hippocampal neurons cultures. Hippocampal neurons were prepared from E18-E19 rat hippocampus as described in Banker and Goslin (1988). Mouse hippocampal neurons were established from the hippocampus of E16-E17 pups derived from breeding of p140 $\mathrm{Cap}^{+/-}$mice, or $p 140 \mathrm{Cap}^{+/-}$female with $\mathrm{p} 140 \mathrm{Cap}^{-1-}$ male. The dissociated cells were plated onto glass coverslips coated with poly-L-

\footnotetext{
$\leftarrow$

(Figure legend continued.) (fEPSP)-evoked stimulating layer II/III on the temporal side of the recording electrode is plotted against stimulus amplitude in p140Cap ${ }^{+/+}(n=10$ slices $)$ and in p140Cap ${ }^{-/-}(n=11$ slices) mice. Two-way repeated-measures ANOVA, stimulus intensity $\times$ genotype, stimulus intensity and interaction intensity $\times$ genotype, $p<0.001$. For a given stimulus intensity: ${ }^{*} p<0.05,{ }^{* *} p<0.01$, Holm-Sidak post hoc test. $\boldsymbol{F}$, Mean fEPSP amplitude recorded at $50 \%$ of response amplitude range in $p 140 \mathrm{Cap}^{+/+}$and $p 140 \mathrm{Cap}^{-/-}$mice ( $t$ test, $p=0.019) . \mathbf{G}, \boldsymbol{H}, p 140 \mathrm{Cap}^{-/-}$mice display impaired motor memory. Performance in motor memory is reported as latency to fall from the rota-rod apparatus. $G$, Mean time to fall during weekly sessions, for five consecutive sessions. $\boldsymbol{H}$, Mean performance in the first trial of each session reported in C. One-way ANOVA test with post-test Bonferroni.
}

lysine. The cells were maintained in Neurobasal (Invitrogen) with B27 supplement and antibiotics, $2 \mathrm{~mm}$ glutamine, and glutamate. Rat and mouse hippocampal neurons were transfected with Lipofectamine 2000 (Invitrogen) respectively at 18 DIV and at 15-16 DIV, and fixed at 21 DIV and 18-20 DIV.

Immunofluorescence and microscopy. Immunofluorescence staining was performed using the following antibodies: PSD95 (1:300; monoclonal; Abcam), Bassoon (1:200; monoclonal; Abcam). p140Cap polyclonal antibody was generated as described in Di Stefano et al. (2004) and used 1:750 phalloidin (1:250, Alexa Fluor 488-phalloidin; 1:250, Alexa Fluor 568-phalloidin; 1:30, Alexa Fluor 350-phalloidin; Invitrogen), myc tag (1:200; monoclonal; produced in house). The counterstaining of nuclei was performed with DAPI (Sigma-Aldrich) for 2 min. Images were acquired using a Leica SPE confocal microscope and Zeiss Axiovert $200 \mathrm{M}$ with Apotome module.

Western blot analysis. Brain proteins were extracted with lysis buffer [1\% Triton X-100, $150 \mathrm{~mm}$ sodium chloride, $50 \mathrm{~mm}$ Tris- $\mathrm{HCl}, \mathrm{pH} 7.5$, protease inhibitors (Roche), $1 \mathrm{~mm}$ phenylmethylsulphonyl fluoride, 1 mM sodium vanadate, $1 \mathrm{~mm}$ sodium fluoride, $1 \mathrm{~mm}$ DTT]. Equal amounts of proteins were resolved by reducing SDS-PAGE and transferred to nitrocellulose filters, which were incubated with the indicated antibodies and developed by using the ECL system. Fractionation experiments and immunoprecipitation from crude synaptosomes were performed essentially as described previously in Schubert et al. (2006).

Antibodies and reagents. Mouse monoclonal to vinculin, rabbit polyclonal to Src, rabbit polyclonal to RhoA, and mouse monoclonal to phosphotyrosine were purchased from Santa Cruz Biotechnology. Rabbit polyclonal to Src phosphotyrosine 416, Rabbit polyclonal to cofilin phosphoserine 3, rabbit polyclonal to cortactin, and rabbit polyclonal to Y421 phosphocortactin were from Cell Signaling Technology. Mouse monoclonal to $\beta$-tubulin, mouse monoclonal to cofilin, rabbit polyclonal to p190RhoGAP, and rabbit monoclonal to p190RhoGAP were from Abcam. Monoclonal antibody to c-Src used for immunoprecipitation and kinase assay was from Calbiochem/Merck Millipore. Mouse monoclonal to p140Cap used for immunoprecipitation and rabbit polyclonal to p140Cap for Western blot were made in house as described in Di Stefano et al. (2007). Rabbit polyclonal to Cit- $\mathrm{N}$ was produced as described in Camera et al. (2003).

Cell lines and $c D N A$. Human embryonic kidney HEK-293 cells were obtained from American Type Culture Collection and cultured in DMEM with 10\% FCS and penicillin/streptomycin. p140Cap cDNA tagged with GFP was produced as described previously (Di Stefano et al., 2007). Cit-N and Cit-N $\Delta$ Rho tagged with myc were produced as described in Camera et al. (2003). p-EGFP and p-mRFP vector were from Clontech.

\section{Results}

\section{p140Cap is required for proper memory consolidation and retrieval and for normal synaptic plasticity}

p140Cap is a scaffold protein whose domain organization (Di Stefano et al., 2004; Repetto et al., 2013) is represented in Figure $1 A$. To evaluate its in vivo role, we generated p140Cap knock-out mice and inserted a neomicin selection cassette within exon 8 (Fig. $1 B, C$ ) to disrupt p140Cap, the p140Cap gene. In homozygous mice, this mutation completely abolished the production of p140Cap, which is normally expressed in at least two main protein isoforms (Fig. 1D). Accordingly, in heterozygous animals, the amount of p140Cap was reduced to $\sim 50 \%$ of the amount in the wild-type controls (Fig. 1D). p140Cap knock-out mice were born with the expected Mendelian ratio and did not display overt neurological phenotypes. However, in consideration of the previous results showing that p140Cap is required for normal development and function of DSs (Jaworski et al., 2009), we hypothesized that its absence could affect superior cognitive processes, such as recognition and memory consolidation (Brown and Aggleton, 2001). To test this possibility, we performed ORT, which revealed a reduced performance for $\mathrm{p}_{140 \mathrm{Cap}}{ }^{-1-}$ mice. 
Indeed, in p140Cap ${ }^{+/+}$animals, the mean exploration time was significantly higher for the novel object than for the familiar one, both at $1 \mathrm{~h}$ and at $24 \mathrm{~h}$ after learning. In contrast, $p 140 \mathrm{Cap}^{-/-}$mice were impaired in recognizing the familiar object, as they spent the same time exploring the novel object and the familiar one, both at $1 \mathrm{~h}$ and at $24 \mathrm{~h}$ (Fig. 2A,B). To evaluate whether memory defects detected in p140 Cap ${ }^{-/-}$mice can be correlated to abnormalities in synaptic function and/or plasticity, we performed LTP and LTD measurements on perirhinal cortex of p140Cap ${ }^{-/-}$and control mice. As shown in Figure 2C, LTP was normally induced both in $p 140 \mathrm{Cap}^{-1-}$ and in wild-type mice, but $1 \mathrm{~h}$ after theta burst stimulus, the level of potentiation fell to baseline in p140Cap ${ }^{-/-}$mice. Indeed, in the last 15 min of registration, response levels were still potentiated in control slices, but returned to baseline in slices from p140 Cap ${ }^{-/-}$mice. p140Cap ${ }^{-1-}$ mice also displayed reduced LTD compared with p140Cap ${ }^{+/+}$mice (Fig. 2D). In addition to these abnormalities in synaptic plasticity, the evoked field response upon progressive increase of the stimulation amplitude was significantly lower than for p140Cap ${ }^{+/+}$control animals (Fig. 2E). These data were further supported by the evidence that the normalized EPSP response amplitude at $50 \%$ of range was significantly lower in p140Cap ${ }^{-/-}$animals compared with controls (Fig. $2 F$ ).

In addition to ORT, we also performed rota-rod test to evaluate motor skill learning. After a training session composed of three trials, $p 140 \mathrm{Cap}^{-/-}$and control mice were weekly analyzed with five consecutive sessions. Although the mean time to fall was not statistically different (Fig. 2G), the mean performance in the first trial of each session revealed that $p 140 \mathrm{Cap}^{-1-}$ mice, at the beginning of the test, have a significantly shorter latency to fall than control mice (Fig. 2H).

Altogether, these results indicate that the absence of p140Cap affects both the basic efficiency of synaptic transmission and the establishment/maintenance of activity-dependent changes.

\section{p140 $\mathrm{Cap}^{-/-}$mice show disorganization in DS distribution and spine dysmorphogenesis}

Considering the strong morphological DS phenotype produced in primary neurons by acute p140Cap knockdown (Jaworski et al., 2009), we asked what are the consequences in vivo when p140Cap is completely missing during brain development. We therefore assessed spine density and morphology using DiOlistic labeling and confocal microscopy of cortical and hippocampal

A

C

D
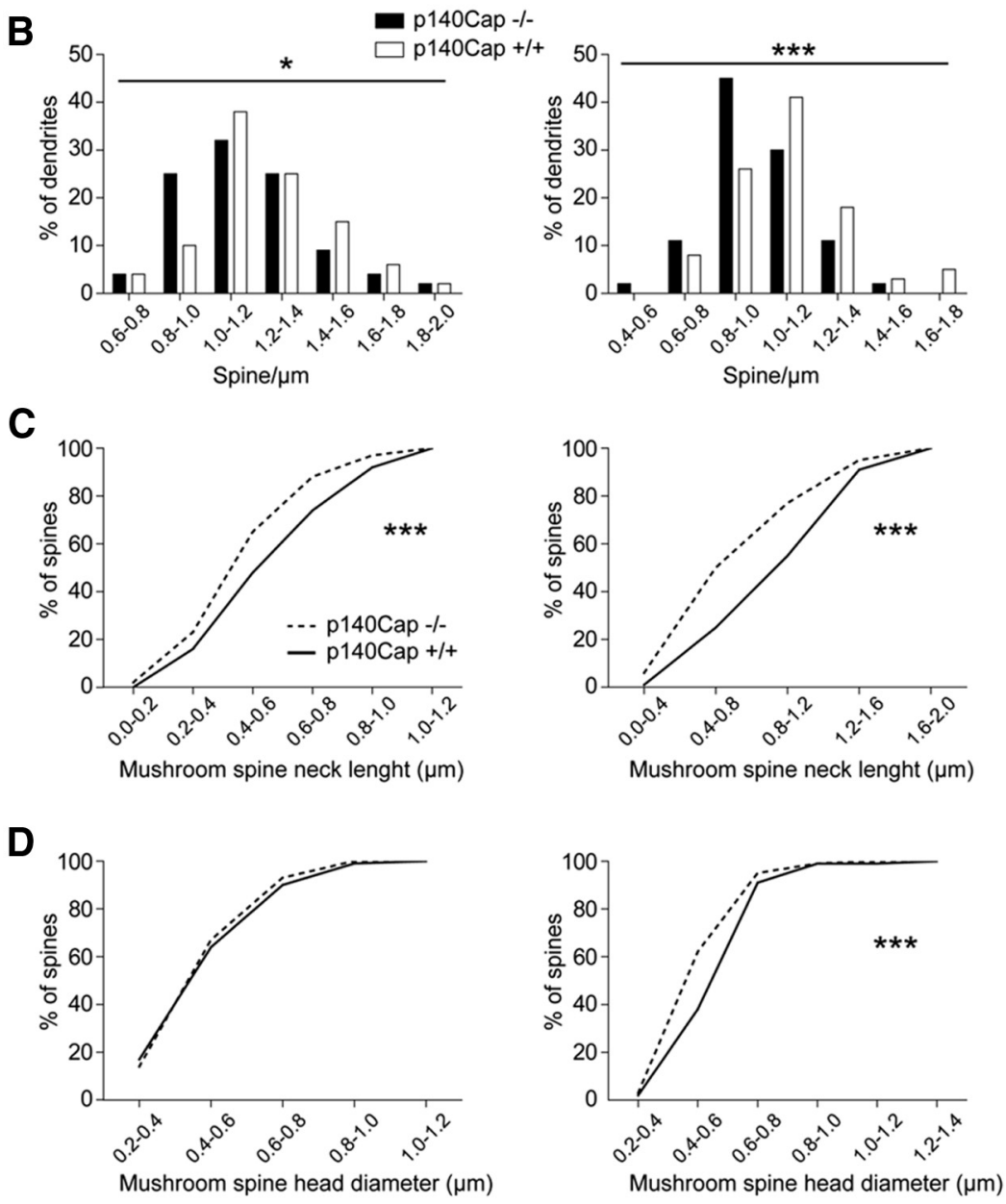

Figure 3. p140Cap ${ }^{-1-}$ mice show abnormal organization and morphology of DSs. A, Representative confocal micrographs showing DiOlistic fluorescent labeling of DSs protruding from hippocampus CA1 (left) and layer V cortical (right) pyramidal neurons in apical dendrites of 1-month-old $p 140 \mathrm{Cap}^{-1-}$ and age-matched wild-type littermates. $\boldsymbol{B}-\boldsymbol{D}$, Quantitative analysis of the frequency distribution of spine density $(\boldsymbol{B})$, spine neck lengths $(\boldsymbol{C}$, and spine head diameters $(\boldsymbol{D})$ in the stratum radiatum of the $C A 1$ area of the hippocampus (left) and in the layer $V$ of the $S 1$ cortex (right). Scale bars, $2 \mu \mathrm{m} ;{ }^{* *} p<0.05,{ }^{* * *} p<0.001 ; n=5$ for each genotype.

pyramidal cells in 1-month-old control and mutant mice (Fig. $3 A$ ). Interestingly, although the overall density of DSs did not differ significantly between wild-type and knock-out mice, in p140 $\mathrm{Cap}^{-1-}$ mice pyramidal neurons of both areas displayed a lower frequency of dendrites with high spine density (Fig. $3 B ; n=$ 5, $\chi^{2}$ test: hippocampus, $p<0.05$; cortex, $\left.p<0.001\right)$. In addition, the morphology of spines also differed between mutant and wildtype mice. In $p 140 \mathrm{Cap}{ }^{-/-}$neurons, there was a significant decrease in the neck length of mushroom-shaped spines (Fig. 3C) both in the stratum radiatum of hippocampus CA1 area $(n=5$, $\chi^{2}$ test, $\left.p<0.01\right)$ and in the layer V of the S1 cortex $\left(n=5, \chi^{2}\right.$ test, 
A
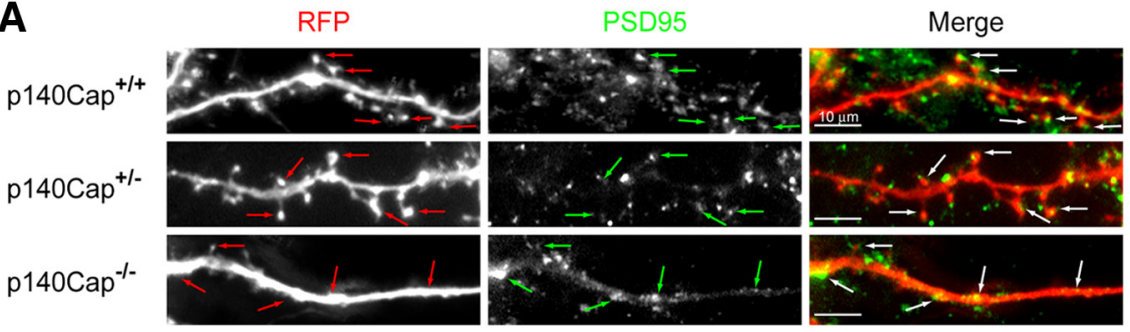

B

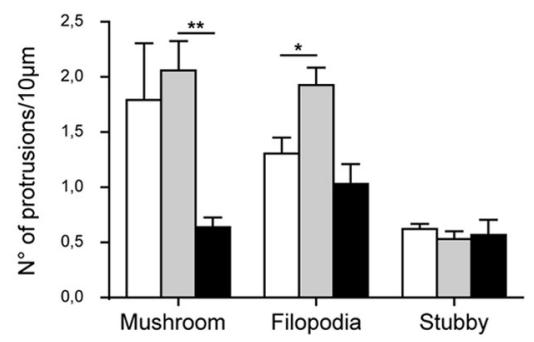

C

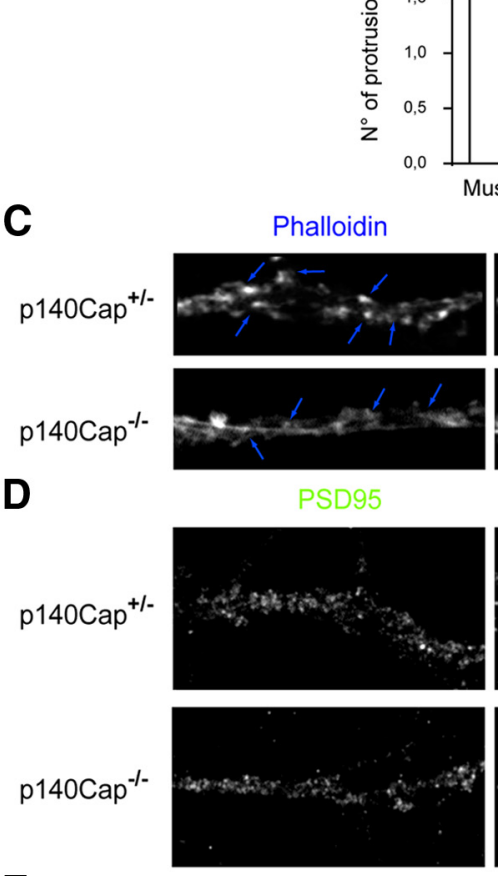

D
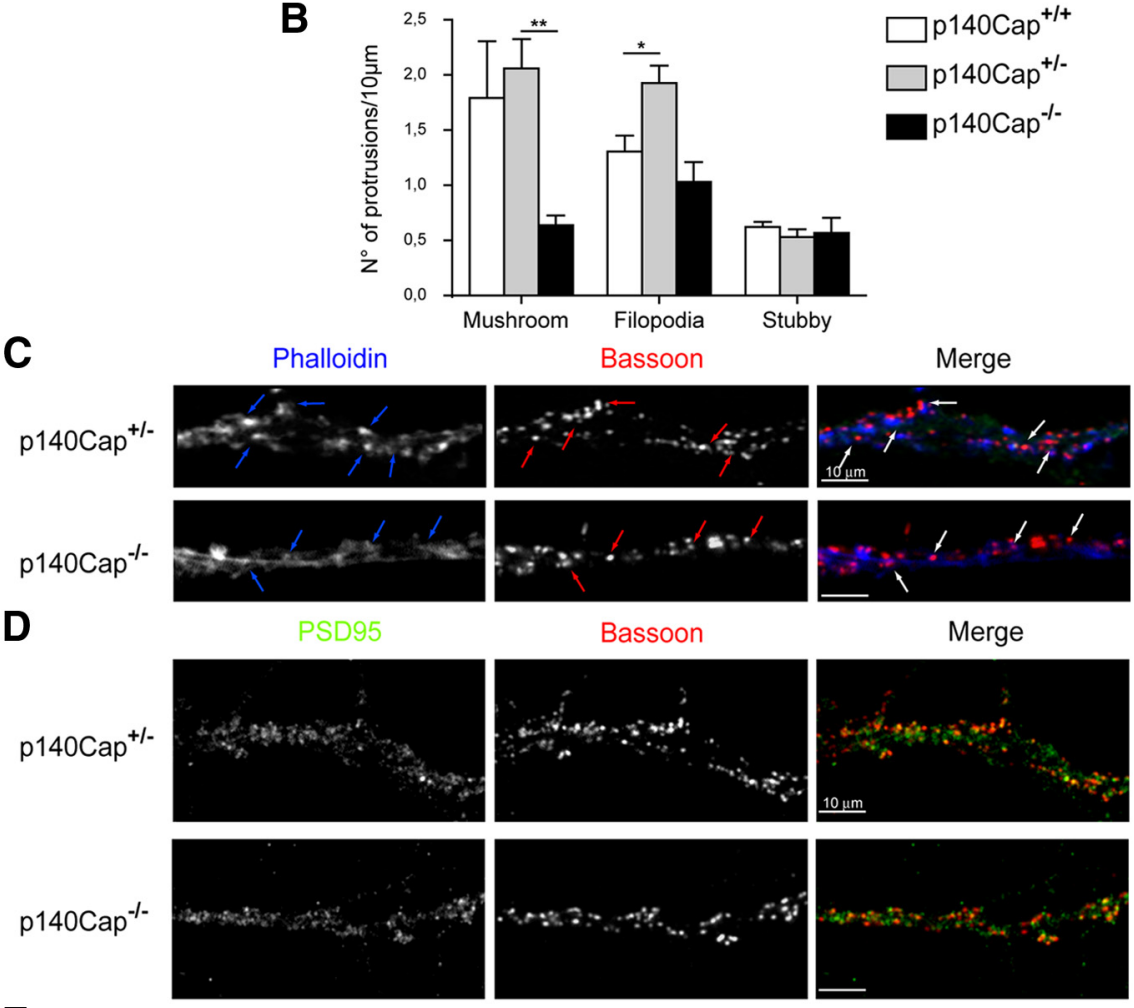

E

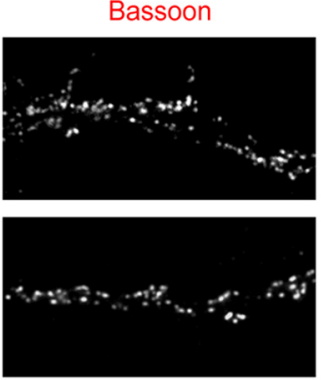

PSD95
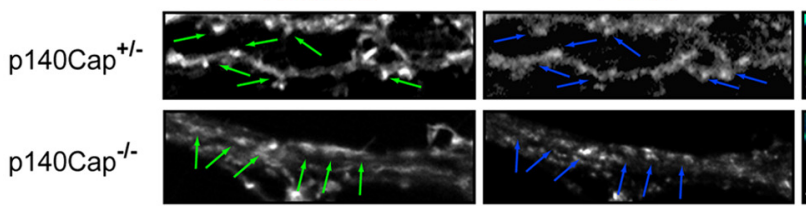

\section{$\mathbf{F}$}

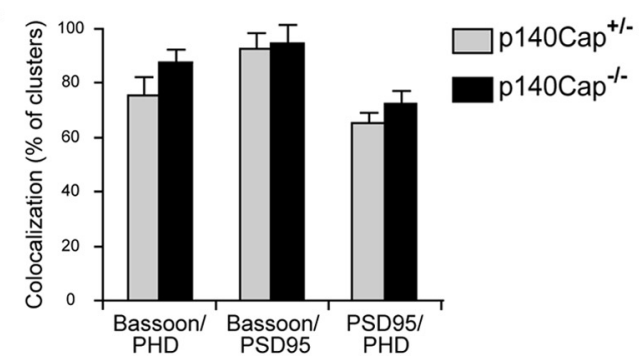

Figure 4. $\quad$ p140Cap ${ }^{-1-}$ cultured hippocampal neurons show reduction of mature mushroom-shaped dendritic spines and actin disorganization. $\boldsymbol{A}, \boldsymbol{B}$, Primary hippocampal neurons from mice of the indicated genotypes were transfected at 18 DIV with $\mathrm{p}$-mRFP for indications of protrusions filling in (red). At 21 DIV, neurons were fixed, stained for postsynaptic density marker PSD95 (green), and processed for immunofluorescence $(\boldsymbol{A})$. The different types of protrusions were then quantified in the intermediate tract of dendrites $(\boldsymbol{B})$ and differences were evaluated by one-way ANOVA test with post-test Bonferroni. ${ }^{*} p<0.05 ;{ }^{* *} p<0.01$. $\mathbf{C}-\boldsymbol{F}$, Primary hippocampal neurons from mice of the indicated genotypes were processed for immunofluorescence at $21 \mathrm{DIV}$ and stained for F-actin with phalloidin (C, $\boldsymbol{E})$, for the presynaptic marker Bassoon $(\boldsymbol{C}, \boldsymbol{D})$, or for the postsynaptic marker PSD95 $(\boldsymbol{D}, \boldsymbol{E})$. The intermediate tracts of representative dendrites are shown. $\boldsymbol{D}$, Arrows, Actin accumulations juxtaposed to Bassoon clusters. $\boldsymbol{F}$, Arrows, Actin accumulations colocalizing with PSD95 clusters. The colocalization between the above signals was quantified $(\boldsymbol{F})$ by measuring the percentage of the first indicated immunoreactivity clusters that overlapped or closely juxtaposed with clusters of the second immunoreactivity. Note that no statistically significant differences in colocalization were observed between genotypes. Scale bars, $10 \mu \mathrm{m}$. $p<0.001$ ), while the head size of spines (Fig. 3D) was significantly reduced in mutant cortices $\left(n=5, \chi^{2}\right.$ test, $\left.p<0.01\right)$ compared with wild-type animals but was normal in the hippocampus.

Reduced mushroom spine number and abnormal F-actin clustering in primary p140 Cap ${ }^{-/-}$hippocampal neurons

The above data suggest that, in vivo, the absence of p140Cap significantly affects synaptic function and plasticity but has a milder effect on spine density than that previously shown in knock-down studies performed in vitro (Jaworski et al., 2009). Therefore, to avoid the implication of the noncell-autonomous cues that may attenuate the in vivo phenotype, we resorted to hippocampal neurons in primary culture, prepared from $p 140 \mathrm{Cap}^{+/+}, \mathrm{p} 140 \mathrm{Cap}^{+/-}$, and p140Cap ${ }^{-1-}$ embryos (Banker and Goslin, 1988). After 21 DIV, p140Cap ${ }^{+/+}$ and $p 140 \mathrm{Cap}^{+/-}$neurons displayed a similar density of mushroom spines, as judged both by RFP filling (Fig. 4A,B) and phalloidin staining (Fig. 4C,E). The only significant difference between p140 Cap ${ }^{+/+}$and p140Cap ${ }^{+/-}$neurons was a slight but significant increase of filopodial-like spines in the latter (Fig. $4 B)$, confirming that a partial loss of p140Cap, such as the one previously obtained with RNAi-based studies (Banker and Goslin, 1988), may specifically lead to this morphological phenotype. In contrast, the development of DSs was strongly impaired in p140Cap ${ }^{-/-}$primary neurons. Indeed, RFP-filling experiments showed a strong reduction in number of total protrusions, in particular in mushroom spines, without any concomitant increase in dendritic filopodia (Fig. $4 A, B)$. Since p140Cap has been found both in the presynaptic and in the postsynaptic terminals (Ito et al., 2008), it is possible that its absence may prevent, in the in vitro environment, the formation of synaptic contacts or the maturation of DSs. To discriminate between these possibilities, cultured neurons were stained with the presynaptic marker Bassoon and with the postsynaptic marker PSD95, as well as with F-actin, because the accumulation, clustering, and colocalization of these proteins in dendritic protrusions is a consistent feature of mature spines (Zhai et al., 2001). The distribution, the overall morphology (Fig. 4C-E), and the colocalization (Fig. 4F) of Bassoon and PSD95 clusters were comparable in the different genotypes. However, while in neurons expressing p140Cap the clusters were usually localized at the tip of actin-rich 
A
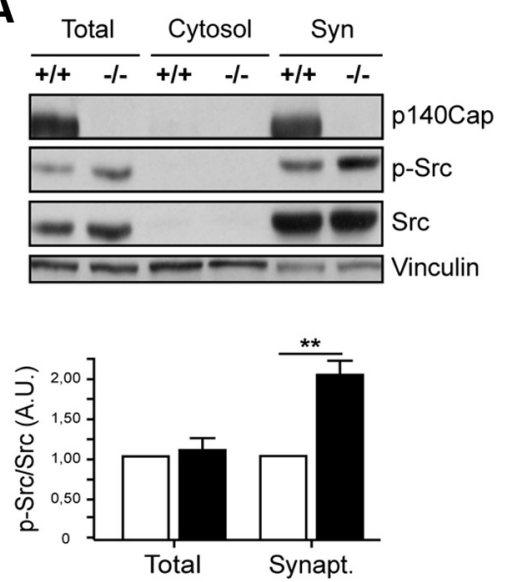

B
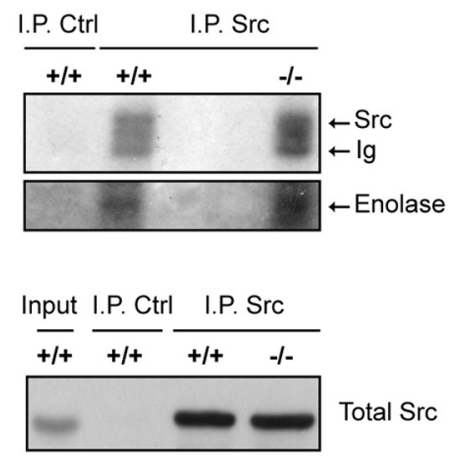

C
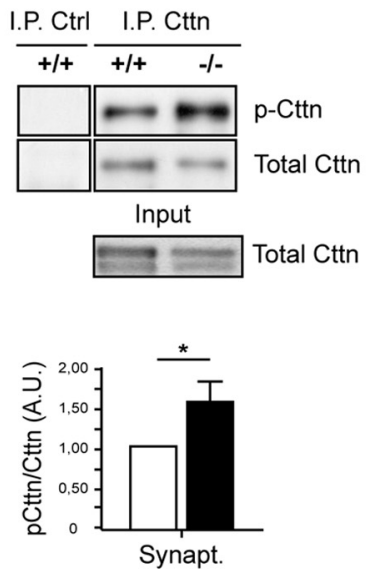

D

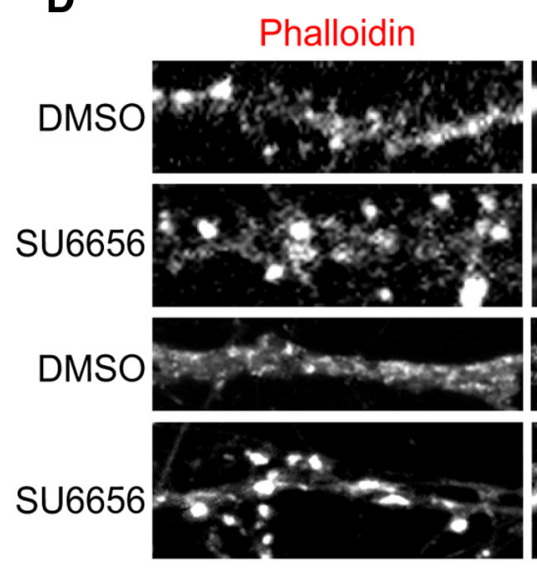

E
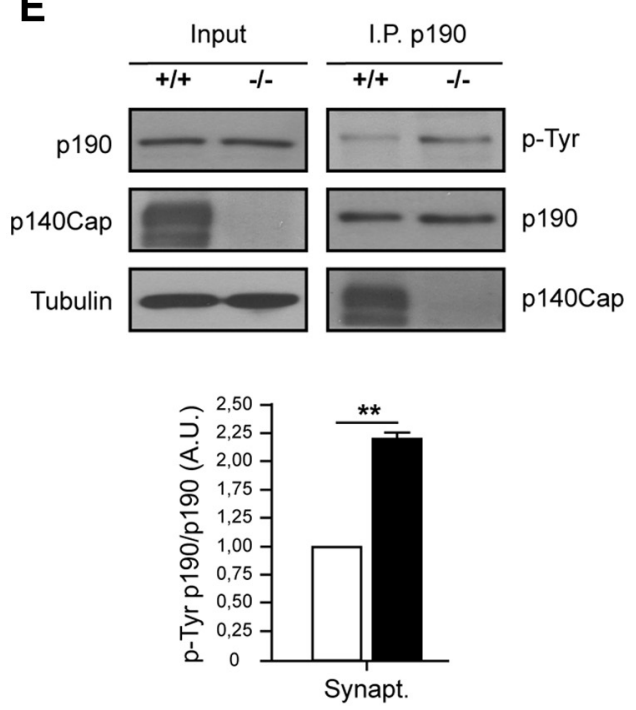

GFP

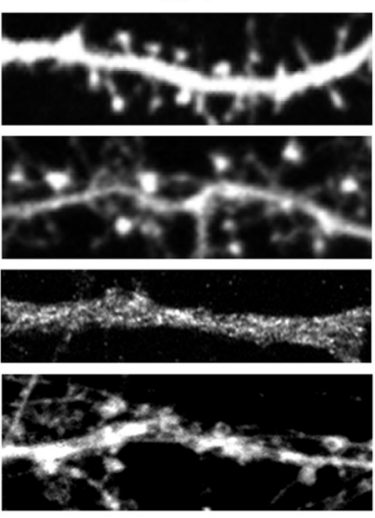

$\mathbf{F}$

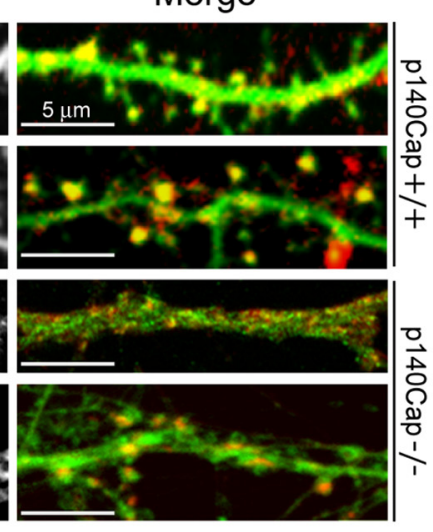

G
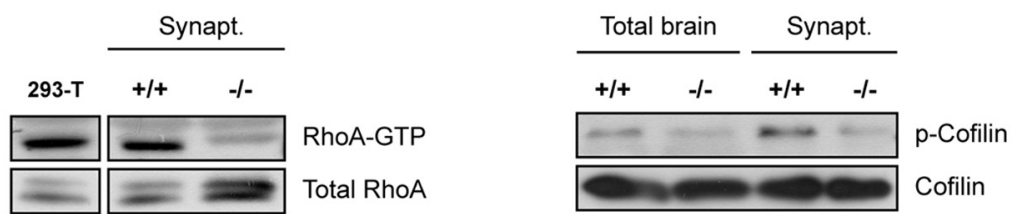

Cofilin
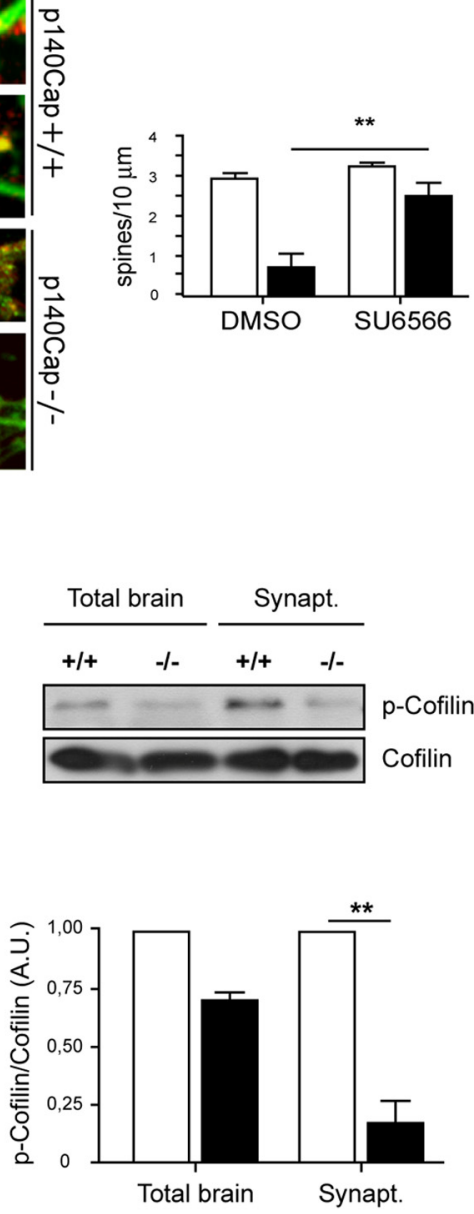

p140Cap ${ }^{+/+} \square$ p140Cap ${ }^{-1}$

Figure 5. p140Cap controls Src and RhoA GTPase activities in synaptosomal fractions. $A$, Total brain extracts, cytosolic fractions, and crude synaptosomal fraction from $p 140$ Cap ${ }^{+/+}$and p140Cap ${ }^{-1-}$ mice were prepared and Western blot analysis was performed with antibodies to p140Cap, active p-Src (Y416), total Src, and vinculin as loading control. B, Top, Kinase assays were performed on Src immunoprecipitated from $p 140 \mathrm{Cap}^{+/+}$and $p 140 \mathrm{Cap}^{-/-}$crude synaptosomal fractions in the presence of the substrate enolase for $30 \mathrm{~s}$. An unrelated polyclonal antibody was used as negative control (Ctrl). The reaction was run on 8\% SDS-PAGE and exposed to autoradiography. Bottom, Half of the above immunoprecipitates, together with $50 \mu \mathrm{g}$ of total cell extract from p140Cap ${ }^{+/+}$synaptosomes (input), was run in parallel $8 \%$ SDS-PAGE and blotted with antibodies to total Src for loading control. C, Protein extracts from synaptosomal fractions of $p 140$ Cap $^{+/+}$ and p140Cap ${ }^{-1-}$ mice were immunoprecipitated with anti-cortactin (Cttn) antibodies. Total and Y421-phosphorylated Cttn were then measured by Western blotting. D, p140Cap ${ }^{+/+}$and p140Cap ${ }^{-1-}$ hippocampal neurons were transfected at 18 DIV with p-EGFP for filling (green). At 21 DIV they were then treated with vehicle (DMS0) or with $10 \mu \mathrm{m} \mathrm{SU6656} \mathrm{Src} \mathrm{kinase} \mathrm{inhibitor} \mathrm{for}$ $16 \mathrm{~h}$, fixed, and stained with phalloidin. The density phalloidin-positive mushroom spines was then quantified. Scale bars, $5 \mu \mathrm{m}$. E, Synaptosomal fractions from p $140 \mathrm{Cap}^{+/+}$and $p 140 \mathrm{Cap}^{-/-}$ mice were lyzed in hot Laemmly buffer (Input) or immunoprecipitated with antibodies to p190RhoGAP. Western blot was then performed with antibodies recognizing phosphotyrosine (p-Tyr), p190RhoGAP, p140Cap, and tubulin for loading control. $\boldsymbol{F}$, Synaptosomal fractions from p140Cap ${ }^{+/+}$and p140Cap ${ }^{-/-}$mice were adsorbed to (Figure legend continues.) 
protrusions, in p140Cap ${ }^{-/-}$neurons, Bassoon and PSD95 clusters were in close proximity to the dendritic shaft (Fig. $4 A, C-F$ ). In addition, and even more strikingly, although the Bassoon juxtaposition and the PSD95 colocalization with F-actin were in general preserved, in $p 140 \mathrm{Cap}^{-/-}$neurons, F-actin labeling was not seen to protrude from dendritic shafts and was characterized by an abnormally elongated morphology (Fig. 4C,E). Altogether, these results suggest that in $140 \mathrm{Cap}^{-1-}$ neurons, the synaptic contacts are normally established, while the protrusive ability of postsynaptic F-actin is compromised, reflecting on the number of mushroom spines.

\section{Synaptic fractions from $p 140 \mathrm{Cap} p^{-/-}$mice display hyperactive Src and reduced RhoA GTPase signaling}

Since p140Cap was originally described as an inhibitor of Src kinases (Di Stefano et al., 2007; Damiano et al., 2010, 2012), we asked whether Src activity was increased in the postnatal brain of p140 Cap $^{-/-}$mice. Western blot analysis performed with antibodies raised against the phosphorylated tyrosine 416 of c-Src, recognizing the activated protein, revealed no differences between total brain lysates of control and $p 140 \mathrm{Cap}^{-1-}$ animals (Fig. $5 A$ ). However, when this analysis was performed on crude synaptosomal preparations extracted from the same animals, a significant twofold increase was detected in p140Cap ${ }^{-/-}$ synaptosomal fractions (Fig. $5 A$ ). This result was confirmed by directly measuring the activity of Src kinases immunoprecipitated from $\mathrm{p} 140 \mathrm{Cap}^{+/+}$and $\mathrm{p} 140 \mathrm{Cap}^{-/-}$synaptosomal fractions (Fig. $5 B$ ). Accordingly, we found in $p 140 \mathrm{Cap}{ }^{-/-}$synaptosomes a significant increase of the tyrosine phosphorylation of cortactin, which is one of the most prominent substrates of Src (Fig. $5 C$ ). Src kinase is a known upstream regulator of actin cytoskeleton (Cabodi et al., 2010). Thus, to evaluate the functional relevance of Src hyperactivation in $p 140 \mathrm{Cap}^{-/-}$mice, we investigated whether the actin phenotype detected in $p 140 \mathrm{Cap}^{-1-}$ primary neurons could be rescued by reducing Src activity. Importantly, an acute treatment $(16 \mathrm{~h})$ with the pharmacological Src inhibitor SU6656 restored normal F-actin organization in p140Cap $^{-/-}$ neurons, with almost complete disappearance of the elongated membrane-associated F-actin and with the appearance of actinenriched mushroom spines (Fig. 5D). The same treatment on wild-type neurons produced only a significant increase in the head size of mushroom DSs (vehicle, $0.72 \pm 0.04 \mu \mathrm{m}$; SU6656, $0.96 \pm 0.06 \mu \mathrm{m}, p<0.01$, Student's $t$ test) without significantly altering their density (Fig. 5D). These data indicate that the absence of p140Cap results in a Src activity-mediated defect in actin organization at DSs, raising the question of which events can occur as a consequence of Src hyperactivation.

In this regard, it has been shown that the Src substrate cortactin may inhibit the actin-depolymerizing factor cofilin by directly binding to it, but that it loses this power to inhibit upon Srcmediated phosphorylation (Oser et al., 2009). Moreover, Src could regulate actin organization through the small GTPase RhoA (Arthur et al., 2000), which is a known regulator of cofilin activity and of DS actin organization (Lin and Webb, 2009; Mu-

\section{$\leftarrow$}

(Figure legend continued.) GST-mammalian diaphanous formins for assessing RhoA activity (Kimura et al., 2000). HEK-293 cells were used as positive control. Western blot was performed with RhoA antibodies. G, Top, Synaptosomal fraction from p140Cap ${ }^{+/+}$and p140Cap ${ }^{-/-}$ mice were blotted with antibodies to p-cofilin (Ser 3) and total cofilin. All the total lysates and the synaptosomal preparations used for this figure were obtained from $6-7$ pulled mice brains for each genotype. In all quantifications, values represent the average of three independent preparations. Error bars, SE; ${ }^{*} p<0.05,{ }^{* *} p<0.01$; two-tailed paired Student's $t$ test. rakoshi et al., 2011). Indeed activated RhoA, through the ROCK/ LIMK pathway, inhibits cofilin by inducing its phosphorylation on Ser-3, thereby triggering proper DS remodelling (Pontrello and Ethell, 2009; Shi et al., 2009; Pontrello et al., 2012). On the other hand, activated Src phosphorylates the RhoA-specific GTPase-activating protein (GAP) p190RhoGap, thereby inducing its GAP activity and decreasing the levels of GTP-RhoA (Brouns et al., 2001; Tamura et al., 2006; Sfakianos et al., 2007). Consistent with these potential mechanisms, we found that synaptosomal fractions extracted from $p 140 \mathrm{Cap}^{-/-}$mice display increased levels of tyrosine-phosphorylated p190RhoGAP (Fig. $5 E$ ), reduced levels of active RhoA, as assessed by pull-down assays (Fig. 5F), and decreased levels of Ser-3 phosphocofilin (Fig. $5 G)$. Altogether, these results suggest that the strong rearrangement of DS actin elicited by p140Cap loss may be caused by an increased Src-dependent inactivation of the RhoA pathway and by cortactin hyperphosphorylation, resulting in abnormal levels of active cofilin.

\section{p140Cap controls spine morphology by interacting with the DS-specific scaffold protein Cit-N}

The maintenance of an adequate organization of actin at spines requires precise spatial localization and organization of the machinery controlling actin assembly at synaptic contacts, a task that is presumably accomplished by proteins associated with the PSD (Pontrello and Ethell, 2009; Hotulainen and Hoogenraad, 2010). Among them, Cit- $\mathrm{N}$ is an attractive candidate for mediating the effects of p140Cap. Indeed, Cit-N is a RhoA-binding protein that has previously been localized to the PSD (Furuyashiki et al., 1999; Zhang and Benson, 2006). Moreover Cit-N forms a complex with several molecules involved in the RhoA pathway (Camera et al., 2003) and is required for spine maintenance in vitro and in vivo through the local recruitment of active RhoA (Camera et al., 2008).

For these reasons, we asked whether p140Cap and Cit-N may physically and functionally interact in DSs. Coimmunoprecipitation assays revealed that p140Cap and Cit-N are able to form a physical complex in vivo, and that this complex also contains Src (Fig. 6A). Interestingly, in total brain extracts from p140 Cap $^{-1-}$ mice, the amount of Src coimmunoprecipitated with Cit-N was lower than in controls (Fig. 6A). The physical association of these three proteins was further confirmed by detecting Cit-N and p140Cap in Src immunoprecipitates obtained from synaptosomal fractions (Fig. 6B). The association between Cit-N and Src was detectable even in the p140Cap ${ }^{-/-}$mice, but the amount of Cit-N coimmunoprecipitated with $\mathrm{Src}$ was lower than in the p140 Cap ${ }^{+/+}$controls (Fig. 6B). These results indicate that Cit-N and Src are capable of interacting both in the presence and in the absence of p140Cap and that the presence of p140Cap significantly increases their interaction. This possibility was further confirmed by overexpressing p140Cap and Cit-N in HEK293 non-neuronal cells and by verifying that the coimmunoprecipitation of the overexpressed Cit-N with endogenous Src can be enhanced by p140Cap (Fig. 6C). The amount of Cit-N coimmunoprecipitated with Src from HEK293 exogenously expressing the latter protein was also increased by treatment with the Src inhibitor SU6656, indicating that the increased association between Src and Cit-N induced by p140Cap overexpression could be due to reduced Src activity (Fig. 6D). We then asked whether the knock-out of p140Cap can modify the association between Cit-N-related and RhoA-related molecules in synaptosomal fractions, and we found a significant reduction of Rock-II (Fig. 6E). Moreover, we found that cortactin can be consistently coimmu- 
A

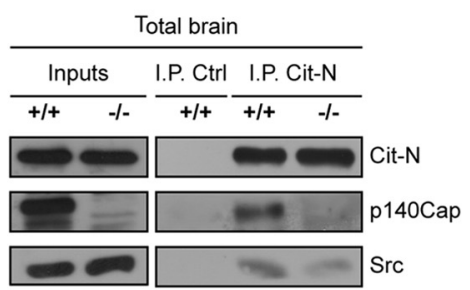

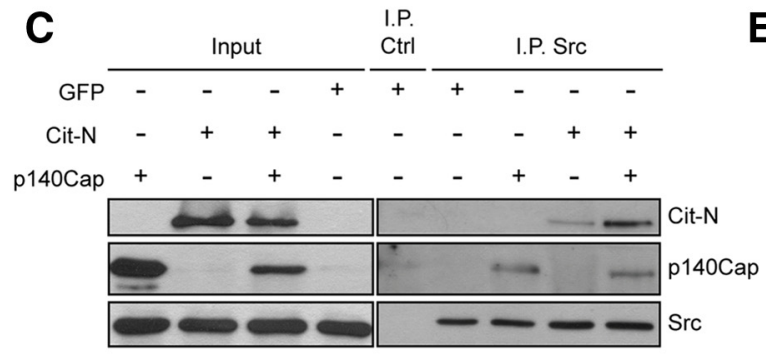

D

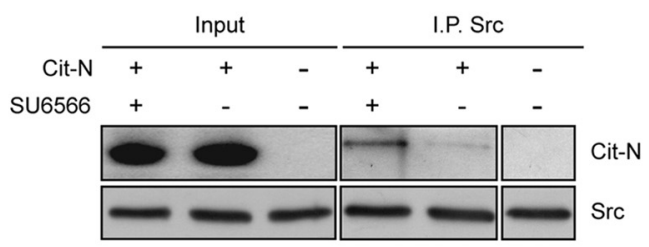

B

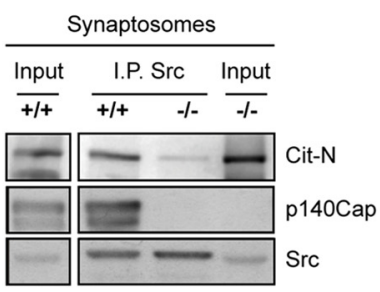

E
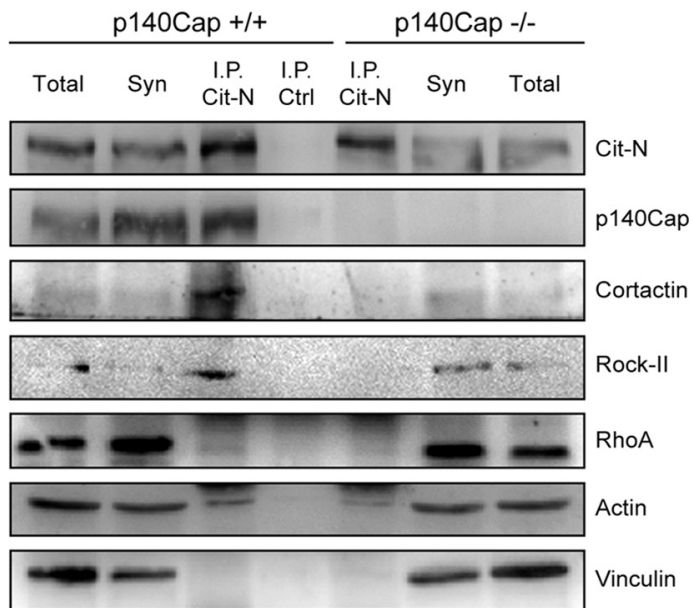

$\mathbf{F}$

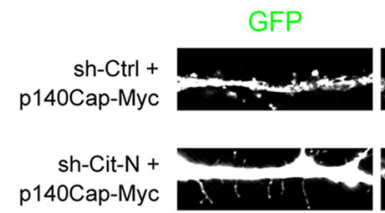

p140Cap Myc
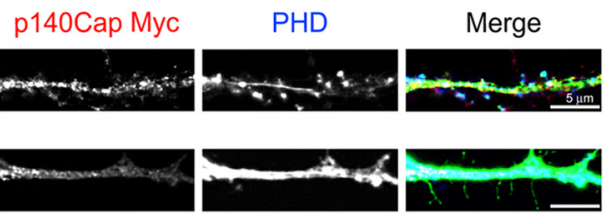

G
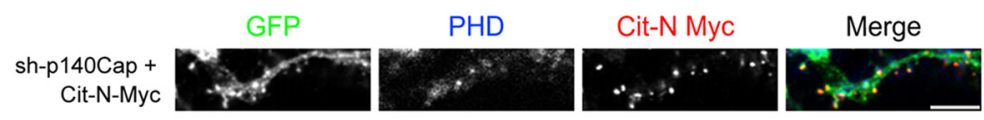

H
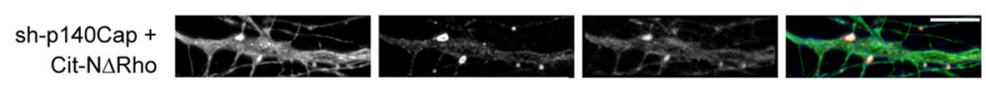

I
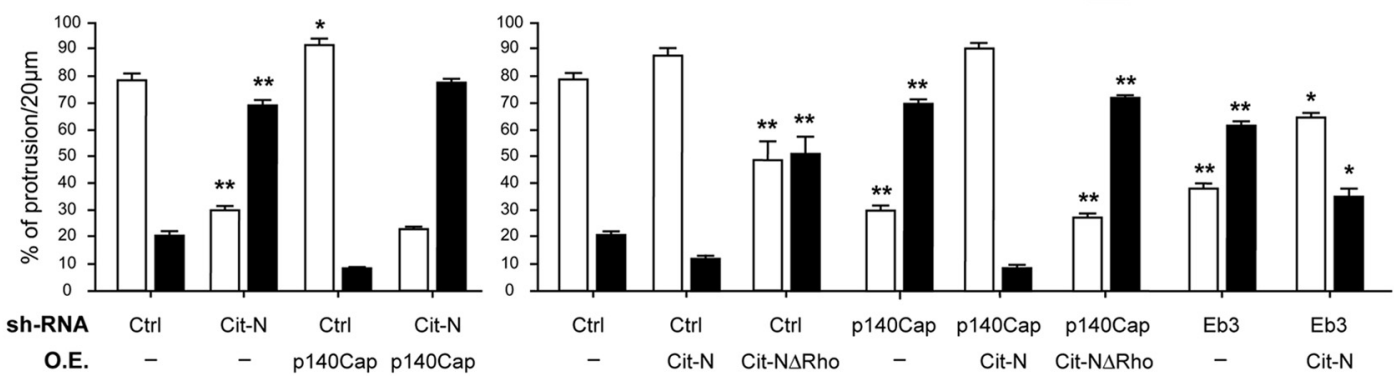

Figure 6. p140Cap interacts with DS-specific scaffold protein Cit-N for the regulation of spine morphology. A, Total brain extracts from $p 140 \mathrm{Cap}{ }^{+/+}$and $p 140 \mathrm{Cap}{ }^{-/-}$mice, obtained as in Figure 5, were immunoprecipitated with antibodies to Cit-N. Western blot was performed with antibodies to Cit-N, p140Cap, and Src. B, Synaptosomal fractions from p140Cap ${ }^{+/+}$and p140Cap ${ }^{-/-}$mice, obtained as in Figure 5, were immunoprecipitated with antibodies to Src. Western blot was performed with antibodies to Cit-N, p140Cap, and Src. C, HEK-293 cells were transfected with p-EGFP, Cit-N, and p140Cap expression constructs as indicated. At $72 \mathrm{~h}$, cell extracts were immunoprecipated with antibodies to Src. Western blot was performed with antibodies to Cit-N, p140Cap, and Src. D, HEK-293 cells were transfected with Cit-N expression construct as indicated and $48 \mathrm{~h}$ later were treated with $10 \mu \mathrm{m}$ SU6656 Src kinase inhibitor or vehicle (DMSO) for an additional $16 \mathrm{~h}$. Cell extracts were then immunoprecipated with antibodies to Src. Western blot was performed with antibodies to Src and Cit-N. E, Synaptosomal fractions from p $140 \mathrm{Cap}{ }^{+/+}$and $p 140 \mathrm{Cap}{ }^{-/-}$mice, obtained as in Figure 5, were immunoprecipitated with antibodies to Cit-N. Immunoprecipitates were run with total extracts from brain or synaptosomes. Western blot was then performed with the indicated antibodies. In all the cases shown above, blots are representative examples of $\geq 3$ independent biological replicates. $\boldsymbol{F}-\boldsymbol{H}$, Primary rat hippocampal neurons were cotransfected at 18 DIV with p-EGFP for filling (green), alongside with the indicated myc-tagged expression constructs and with the indicated shRNA plasmids (Camera et al., 2008; Jaworski et al., 2009). At 21 DIV, neurons were fixed and stained with antibodies anti-GFP and anti-myc and with phalloidin (PHD). Scale bars, $5 \mu \mathrm{m}$. I, Quantification of mushroom spines (white box) and filopodial protrusions (black box) in middle dendrites in the above experiments, and in a parallel experiment performed with EB3-specific shRNAs. 0.E., Myc-tagged overexpression constructs. Histograms represent the average of three independent experiments, with $\geq 6$ cells for every condition. Error bars, SD. Asterisks indicate the statistical significance of the difference with the samples transfected only with control shRNA vector. Two-tailed paired Student's $t$ test. ${ }^{*} p<0.05,{ }^{* *} p<0.01$. 
noprecipitated with Cit-N from control synaptosomes, while it is barely detectable in immunoprecipitation performed on p140 Cap $^{-1-}$ synaptosomes (Fig. 6E).

Next, since the knockdown of p140Cap or of Cit-N by shRNA in primary rat hippocampal neurons results in similar phenotypes, characterized by a decrease of mushroom spines and by an increase of filopodia-like spines (Camera et al., 2008; Jaworski et al., 2009), we took advantage on this ex vivo assay to address the epistatic relationship between these two proteins. The overexpression of p140Cap did not affect the phenotype induced by Cit-N depletion (Fig. $6 F, I$ ). In contrast, the overexpression of wild-type Cit-N restored to control levels the percentage of filopodia and of mushroom spines in p140Cap-silenced neurons (Fig. $6 G, I)$. Interestingly the overexpression of a mutant Cit-N lacking the RhoA binding domain (Cit-N $\Delta$ Rho) induced by itself an increase of filopodia at the expenses of mushroom spines and was unable to rescue the p140Cap knockdown phenotype (Fig. $6 H, I)$. Consistent with EB3-acting upstream p140Cap in spine regulation, the overexpression of Cit- $\mathrm{N}$ was also able to reverse most of the effects of EB3 knockdown (Fig. 6I). Together, our results suggest that, by modulating Src and by interacting with Cit-N, p140Cap can control not only the activity, but also the local recruitment of the Cit- $\mathrm{N}$-associated actin-polymerizing machinery.

\section{Discussion}

The results of recent in vitro studies have underscored the importance of crosstalk between dynamic microtubules and actin organization in DS maintenance and remodelling (Jaworski et al., 2009). The same studies have identified p140Cap as one of the critical molecules for this crosstalk but have left a number of unanswered questions, the first of which concerns the in vivo relevance of its function. By reporting the characterization of the phenotype of p140Cap knock-out mice, we here provide the first demonstration of the importance of this molecule for learning and memory. Indeed, despite a grossly normal neurological phenotype, p140 $\mathrm{Cap}^{-1-}$ mice display distinct abnormalities in the ORT, indicating that this molecule has a critical role in the establishment and consolidation of new declarative memories. In good agreement with these observations, electrophysiological testing of perirhinal cortex revealed reduced basal synaptic transmission and abnormal synaptic plasticity. In particular, we found that long-lasting plasticity is specifically affected by p140Cap deletion, since short-term potentiation is normally established in p140 Cap $^{-1-}$ animals but rapidly decays. Accordingly, we also found that the establishment of LTD is significantly impaired in the knock-outs. Moreover, the slight abnormalities detected in the accelerated rota-rod test suggest that p140Cap may also be required for the efficient maintenance of motor skill learning. The subtle anatomical differences in the distribution and in the morphology of DSs between p140Cap ${ }^{-/-}$mice and their littermate controls are somewhat surprising and provide only a partial explanation of the neuronal modifications involved in the functional phenotypes. Indeed, despite the reduction in the number of spine-rich dendrites observed in $140 \mathrm{Cap}^{-1-}$ mice, the overall density of mature spines is unaffected under basal conditions. Therefore, a general reduction of spine density cannot be invoked as the main cause of the reduced basal synaptic transmission. On the other hand, although spine neck geometry plays a crucial role in compartmentalizing calcium signaling in DSs (Noguchi et al., 2005; Arellano et al., 2007), it is difficult to envisage how the reduction in neck length and head diameter observed in the knock-outs could affect synaptic plasticity. To start solving these

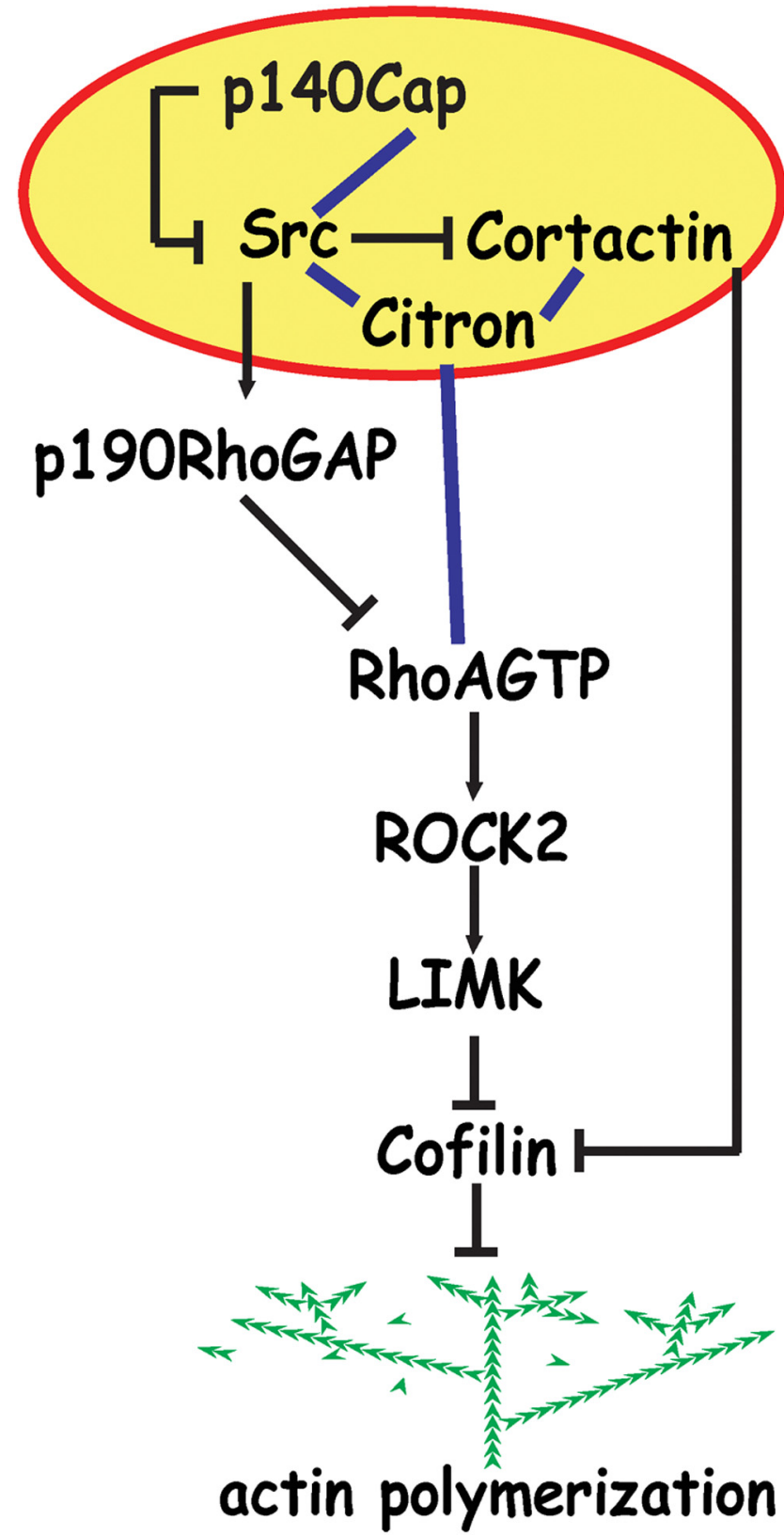

Figure 7. p140Cap controls actin dynamics to promote organization of mushroom DSs. A, Core functional complex that includes p140Cap, Src, Cit-N, and cortactin may control actin organization in DSs. p140Cap can either decrease Src-dependent tyrosine phosphorylation of p190RhoGAP or affect the local recruitment of active RhoA through Cit-N. These two pathways may converge on RhoA activation, which regulates the levels of inactive cofilin. The latter can also be controlled by direct binding to cortactin, which is regulated by Src-mediated phosphorylation. Thus, p140Cap may locally restrain the activity of cofilin through different Src-mediated pathways, promoting actin polymerization and formation of mushroom spines.

issues, future imaging experiments of DS dynamics in vivo in p140 $\mathrm{Cap}^{-1-}$ mice should be designed to analyze the maturation and the active turnover of DSs, crucial processes for the normal formation and plasticity of neuronal circuits that are closely dependent on actin remodelling (Hanley, 2008; Holtmaat and Svoboda, 2009; Hotulainen and Hoogenraad, 2010).

Intriguingly, in contrast with the in vivo scenario, primary neurons isolated from $p 140 \mathrm{Cap}^{-1-}$ mice are significantly impaired in their ability to form mature spines in vitro. Indeed, a $50 \%$ reduction in protein levels is sufficient to increase the number of filopodial spines, which is in good agreement with the 
knockdown studies performed in rat hippocampal neurons. Meanwhile, total ablation of the gene leads to a sharp decrease in the density of mushroom spines, without increasing the number of filopodia. Most likely, this phenotype is not the result of a reduced capability to form synaptic contacts, but is rather caused by a defective organization of the actin cytoskeleton at postsynaptic sites. Indeed, the distribution and colocalization of presynaptic and postsynaptic markers are essentially normal in knock-out cultures. On the other hand, while F-actin clusters are still significantly colocalized with synaptic markers, they display an abnormally elongated morphology, running parallel to the dendritic shaft membrane rather than protruding from it. A reasonable explanation for the apparent discrepancy between the in vitro and the in vivo data could be that, in the latter situation, noncell-autonomous cues, such as the abundance of trophic factors and cell-cell contacts with neuronal and glial cells, may compensate for the loss of p140Cap in producing DSs normally protruding from shafts. The function of p140Cap may thus be essential only in situations requiring activity-dependent remodelling of actin at spines, such as those linked to LTP and LTD. On the other hand, it is possible that the memory defects and electrophysiological phenotypes are not directly related to actin dynamics but rather depend on other processes, such as AMPA receptor turnover, that have not been linked so far to p140Cap. This hypothesis is particularly intriguing in view of the fact that AMPA receptor turnover is closely correlated with the dynamic changes of DSs (Kopec et al., 2007; Xie et al., 2007; for review, see Hanley, 2008). Further studies are necessary to shed full light on these points.

The second open question concerns the molecular mechanisms by which p140Cap may locally regulate actin dynamics at DSs. The studies so far performed suggested that p140Cap may primarily work by inhibiting the activity of Src kinases at DSs, thereby reducing the phosphorylation of critical substrates, such as cortactin (Jaworski et al., 2009). Our present results provide strong support to this scenario and significantly extend our understanding of how actin cytoskeleton is modulated downstream of these events. Indeed, we found that the activity of Src is significantly increased in synaptosomal preparations obtained from p140Cap knock-out mice and we confirmed that this is accompanied by increased cortactin tyrosine phosphorylation (Fig. 5). Importantly, we also found that the inhibition of Src can restore mature spines in $p 140 \mathrm{Cap}^{-1-}$ neurons, correcting the actindisorganization phenotype. Since localized activation or recruitment of active RhoA is necessary for mushroom DS remodelling and plasticity (Schubert et al., 2006; Murakoshi et al., 2011), exploring the role of the corresponding molecular pathway was the most straightforward possibility to explain how p140Capdependent control of Src activity could modulate actin cytoskeleton. These studies led us to two main conclusions. The first is that p140Cap may control the levels of active RhoA in synaptosomes by decreasing Src-dependent tyrosine phosphorylation of the RhoA-specific GTPase-activating protein p190RhoGAP. The second is that the protein may also affect the local recruitment of active RhoA through Cit-N, a scaffold protein required for spine maintenance (Camera et al., 2008). Cit-N forms a complex with RhoA and with many RhoA-binding proteins, including Rock-II (Camera et al., 2008). The latter mechanism may be of particular functional relevance, because the overexpression of Cit- $\mathrm{N}$ can rescue the effects induced by p140Cap and EB3 knockdown, while the overexpression of a mutant lacking the RhoA-binding domain has no rescue activity and may induce by itself a phenotype similar to p140Cap and Cit-N knockdown. The detection of a physical interaction between Cit-N and Src, which is reproduced in non-neuronal cells and is modulated by p140Cap levels and by Src activity, suggests that the two mechanisms could be physically integrated by Cit-N. Moreover, it is very interesting to notice that the deletion of $140 \mathrm{Cap}$ results in a reduced association of Cit-N with Rock-II and cortactin. The latter molecule has been previously shown to bind p140Cap (Damiano et al., 2012). A likely convergence point of the molecular alterations that we detected in the knock-out synaptosomes could be on the regulation of the actin-depolymerizing factor cofilin. Indeed, Rock-II activates LIMK (Ohashi et al., 2000), which in turn may inhibit cofilin by phosphorylating its Ser-3 residue (Yang et al., 1998). On the other hand, cortactin may inhibit cofilin by directly binding to it, but loses this power to inhibit upon Src-mediated phosphorylation (Oser et al., 2009). A possible model emerging from our results (Fig. 7) is that p140Cap, bound to the plus end of dynamic microtubules, could promote the local polymerization of spine actin through multiple Src-dependent mechanisms converging on decreasing the levels of active cofilin associated with the PSD. Although deeper studies are certainly required to understand whether and how the mentioned molecules modulate DS dynamics in vivo and to dissect how synaptic activity may modulate them, we think that this model could provide a useful framework to explore the relevance and the mechanisms of microtubule-dependent actin remodelling at DSs.

\section{References}

Arellano JI, Benavides-Piccione R, Defelipe J, Yuste R (2007) Ultrastructure of dendritic spines: correlation between synaptic and spine morphologies. Front Neurosci 1:131-143. CrossRef Medline

Arthur WT, Petch LA, Burridge K (2000) Integrin engagement suppresses RhoA activity via a c-Src-dependent mechanism. Curr Biol 10:719-722. CrossRef Medline

Banker G, Goslin K (1988) Developments in neuronal cell culture. Nature 336:185-186. CrossRef Medline

Brouns MR, Matheson SF, Settleman J (2001) p190 RhoGAP is the principal Src substrate in brain and regulates axon outgrowth, guidance and fasciculation. Nat Cell Biol 3:361-367. CrossRef Medline

Brown MW, Aggleton JP (2001) Recognition memory: what are the roles of the perirhinal cortex and hippocampus? Nat Rev Neurosci 2:51-61. CrossRef Medline

Cabodi S, del Pilar Camacho-Leal M, Di Stefano P, Defilippi P (2010) Integrin signalling adaptors: not only figurants in the cancer story. Nat Rev Cancer 10:858-870. CrossRef Medline

Camera P, da Silva JS, Griffiths G, Giuffrida MG, Ferrara L, Schubert V, Imarisio S, Silengo L, Dotti CG, Di Cunto F (2003) Citron-N is a neuronal Rho-associated protein involved in Golgi organization through actin cytoskeleton regulation. Nat Cell Biol 5:1071-1078. CrossRef Medline

Camera P, Schubert V, Pellegrino M, Berto G, Vercelli A, Muzzi P, Hirsch E, Altruda F, Dotti CG, Di Cunto F (2008) The RhoA-associated protein Citron-N controls dendritic spine maintenance by interacting with spineassociated Golgi compartments. EMBO Rep 9:384-392. CrossRef Medline

Chapleau CA, Boggio EM, Calfa G, Percy AK, Giustetto M, Pozzo-Miller L (2012) Hippocampal CA1 pyramidal neurons of Mecp2 mutant mice show a dendritic spine phenotype only in the presymptomatic stage. Neural Plast 2012:976164. CrossRef Medline

Cho K, Kemp N, Noel J, Aggleton JP, Brown MW, Bashir ZI (2000) A new form of long-term depression in the perirhinal cortex. Nat Neurosci 3:150-156. CrossRef Medline

Damiano L, Di Stefano P, Camacho Leal MP, Barba M, Mainiero F, Cabodi S, Tordella L, Sapino A, Castellano I, Canel M, Frame M, Turco E, Defilippi P (2010) p140Cap dual regulation of E-cadherin/EGFR cross-talk and Ras signalling in tumour cell scatter and proliferation. Oncogene 29: 3677-3690. CrossRef Medline

Damiano L, Le Dévédec SE, Di Stefano P, Repetto D, Lalai R, Truong H, Xiong JL, Danen EH, Yan K, Verbeek FJ, De Luca E, Attanasio F, Buccione R, Turco E, van de Water B, Defilippi P (2012) p140Cap suppresses the 
invasive properties of highly metastatic MTLn3-EGFR cells via impaired cortactin phosphorylation. Oncogene 31:624-633. CrossRef Medline

Di Stefano P, Cabodi S, Boeri Erba E, Margaria V, Bergatto E, Giuffrida MG, Silengo L, Tarone G, Turco E, Defilippi P (2004) P130Cas-associated protein (p140Cap) as a new tyrosine-phosphorylated protein involved in cell spreading. Mol Biol Cell 15:787-800. Medline

Di Stefano P, Damiano L, Cabodi S, Aramu S, Tordella L, Praduroux A, Piva R, Cavallo F, Forni G, Silengo L, Tarone G, Turco E, Defilippi P (2007) p140Cap protein suppresses tumour cell properties, regulating Csk and Src kinase activity. EMBO J 26:2843-2855. CrossRef Medline

Furuyashiki T, Fujisawa K, Fujita A, Madaule P, Uchino S, Mishina M, Bito H, Narumiya S (1999) Citron, a Rho-target, interacts with PSD-95/SAP-90 at glutamatergic synapses in the thalamus. J Neurosci 19:109-118. Medline

Hanley JG (2008) AMPA receptor trafficking pathways and links to dendritic spine morphogenesis. Cell Adh Migr 2:276-282. CrossRef Medline

Hering H, Sheng M (2001) Dendritic spines: structure, dynamics and regulation. Nat Rev Neurosci 2:880-888. CrossRef Medline

Holtmaat A, Svoboda K (2009) Experience-dependent structural synaptic plasticity in the mammalian brain. Nat Rev Neurosci 10:647-658. CrossRef Medline

Hotulainen P, Hoogenraad CC (2010) Actin in dendritic spines: connecting dynamics to function. J Cell Biol 189:619-629. CrossRef Medline

Hu X, Ballo L, Pietila L, Viesselmann C, Ballweg J, Lumbard D, Stevenson M, Merriam E, Dent EW (2011) BDNF-induced increase of PSD-95 in dendritic spines requires dynamic microtubule invasions. J Neurosci 31: 15597-15603. CrossRef Medline

Ito H, Atsuzawa K, Sudo K, Di Stefano P, Iwamoto I, Morishita R, Takei S, Semba R, Defilippi P, Asano T, Usuda N, Nagata K (2008) Characterization of a multidomain adaptor protein, p140Cap, as part of a pre-synaptic complex. J Neurochem 107:61-72. CrossRef Medline

Jaworski J, Kapitein LC, Gouveia SM, Dortland BR, Wulf PS, Grigoriev I, Camera P, Spangler SA, Di Stefano P, Demmers J, Krugers H, Defilippi P, Akhmanova A, Hoogenraad CC (2009) Dynamic microtubules regulate dendritic spine morphology and synaptic plasticity. Neuron 61:85-100. CrossRef Medline

Kimura K, Tsuji T, Takada Y, Miki T, Narumiya S (2000) Accumulation of GTP-bound RhoA during cytokinesis and a critical role of ECT2 in this accumulation. J Biol Chem 275:17233-17236. CrossRef Medline

Kopec CD, Real E, Kessels HW, Malinow R (2007) GluR1 links structural and functional plasticity at excitatory synapses. J Neurosci 27:1370613718. CrossRef Medline

Lemieux M, Labrecque S, Tardif C, Labrie-Dion É, Lebel É, De Koninck P (2012) Translocation of CaMKII to dendritic microtubules supports the plasticity of local synapses. J Cell Biol 198:1055-1073. CrossRef Medline

Lin WH, Webb DJ (2009) Actin and actin-binding proteins: masters of dendritic spine formation, morphology, and function. Open Neurosci J 3:5466. CrossRef Medline

Matsuzaki M, Honkura N, Ellis-Davies GC, Kasai H (2004) Structural basis of long-term potentiation in single dendritic spines. Nature 429:761-766. CrossRef Medline

Merriam EB, Lumbard DC, Viesselmann C, Ballweg J, Stevenson M, Pietila L, Hu X, Dent EW (2011) Dynamic microtubules promote synaptic NMDA receptor-dependent spine enlargement. PLoS One 6:e27688. CrossRef Medline

Murakoshi H, Wang H, Yasuda R (2011) Local, persistent activation of Rho GTPases during plasticity of single dendritic spines. Nature 472:100-104. CrossRef Medline

Noguchi J, Matsuzaki M, Ellis-Davies GC, Kasai H (2005) Spine-neck geometry determines NMDA receptor-dependent $\mathrm{Ca} 2+$ signaling in dendrites. Neuron 46:609-622. CrossRef Medline

Ohashi K, Nagata K, Maekawa M, Ishizaki T, Narumiya S, Mizuno K (2000) Rho-associated kinase ROCK activates LIM-kinase 1 by phosphorylation at threonine 508 within the activation loop. J Biol Chem 275:3577-3582. CrossRef Medline
Oser M, Yamaguchi H, Mader CC, Bravo-Cordero JJ, Arias M, Chen X, Desmarais V, van Rheenen J, Koleske AJ, Condeelis J (2009) Cortactin regulates cofilin and N-WASp activities to control the stages of invadopodium assembly and maturation. J Cell Biol 186:571-587. CrossRef Medline

Pavlowsky A, Gianfelice A, Pallotto M, Zanchi A, Vara H, Khelfaoui M, Valnegri P, Rezai X, Bassani S, Brambilla D, Kumpost J, Blahos J, Roux MJ, Humeau Y, Chelly J, Passafaro M, Giustetto M, Billuart P, Sala C (2010) A postsynaptic signaling pathway that may account for the cognitive defect due to IL1RAPL1 mutation. Curr Biol 20:103-115. CrossRef Medline Pontrello CG, Ethell IM (2009) Accelerators, brakes, and gears of actin dynamics in dendritic spines. Open Neurosci J 3:67-86. CrossRef Medline

Pontrello CG, Sun MY, Lin A, Fiacco TA, DeFea KA, Ethell IM (2012) Cofilin under control of beta-arrestin-2 in NMDA-dependent dendritic spine plasticity, long-term depression (LTD), and learning. Proc Natl Acad Sci U S A 109:E442-E451. CrossRef Medline

Repetto D, Aramu S, Boeri Erba E, Sharma N, Grasso S, Russo I, Jensen ON, Cabodi S, Turco E, Di Stefano P, Defilippi P (2013) Mapping of p140Cap phosphorylation sites: the EPLYA and EGLYA motifs have a key role in tyrosine phosphorylation and Csk binding, and are substrates of the Abl kinase. PLoS One 8:e54931. CrossRef Medline

Rex CS, Chen LY, Sharma A, Liu J, Babayan AH, Gall CM, Lynch G (2009) Different Rho GTPase-dependent signaling pathways initiate sequential steps in the consolidation of long-term potentiation. J Cell Biol 186:8597. CrossRef Medline

Schubert V, Da Silva JS, Dotti CG (2006) Localized recruitment and activation of RhoA underlies dendritic spine morphology in a glutamate receptor-dependent manner. J Cell Biol 172:453-467. CrossRef Medline

Sfakianos MK, Eisman A, Gourley SL, Bradley WD, Scheetz AJ, Settleman J, Taylor JR, Greer CA, Williamson A, Koleske AJ (2007) Inhibition of Rho via Arg and p190RhoGAP in the postnatal mouse hippocampus regulates dendritic spine maturation, synapse and dendrite stability, and behavior. J Neurosci 27:10982-10992. CrossRef Medline

Shi Y, Pontrello CG, DeFea KA, Reichardt LF, Ethell IM (2009) Focal adhesion kinase acts downstream of EphB receptors to maintain mature dendritic spines by regulating cofilin activity. J Neurosci 29:8129-8142. CrossRef Medline

Star EN, Kwiatkowski DJ, Murthy VN (2002) Rapid turnover of actin in dendritic spines and its regulation by activity. Nat Neurosci 5:239-246. CrossRef Medline

Tada T, Sheng M (2006) Molecular mechanisms of dendritic spine morphogenesis. Curr Opin Neurobiol 16:95-101. CrossRef Medline

Tamura H, Fukada M, Fujikawa A, Noda M (2006) Protein tyrosine phosphatase receptor type $\mathrm{Z}$ is involved in hippocampus-dependent memory formation through dephosphorylation at Y1105 on p190 RhoGAP. Neurosci Lett 399:33-38. CrossRef Medline

van Spronsen M, Hoogenraad CC (2010) Synapse pathology in psychiatric and neurologic disease. Curr Neurol Neurosci Rep 10:207-214. CrossRef Medline

Xie Z, Srivastava DP, Photowala H, Kai L, Cahill ME, Woolfrey KM, Shum CY, Surmeier DJ, Penzes P (2007) Kalirin-7 controls activity-dependent structural and functional plasticity of dendritic spines. Neuron 56:640 656. CrossRef Medline

Yang N, Higuchi O, Ohashi K, Nagata K, Wada A, Kangawa K, Nishida E, Mizuno K (1998) Cofilin phosphorylation by LIM-kinase 1 and its role in Rac-mediated actin reorganization. Nature 393:809-812. CrossRef Medline

Yoshihara Y, De Roo M, Muller D (2009) Dendritic spine formation and stabilization. Curr Opin Neurobiol 19:146-153. CrossRef Medline

Zhai RG, Vardinon-Friedman H, Cases-Langhoff C, Becker B, Gundelfinger ED, Ziv NE, Garner CC (2001) Assembling the presynaptic active zone: a characterization of an active one precursor vesicle. Neuron 29:131-143. CrossRef Medline

Zhang W, Benson DL (2006) Targeting and clustering citron to synapses. Mol Cell Neurosci 31:26-36. CrossRef Medline 